\title{
Goal-Directed Aiming: Two Components but Multiple Processes
}

\author{
Digby Elliott \\ Liverpool John Moores University and McMaster University
}

\author{
Steve Hansen \\ Liverpool John Moores University and Brock University
}

\author{
Lawrence E. M. Grierson \\ Toronto Rehabilitation Institute, Toronto, Canada
}

\author{
James Lyons \\ McMaster University
}

\author{
Simon J. Bennett and Spencer J. Hayes \\ Liverpool John Moores University
}

\begin{abstract}
This article reviews the behavioral literature on the control of goal-directed aiming and presents a multiple-process model of limb control. The model builds on recent variants of Woodworth's (1899) two-component model of speed-accuracy relations in voluntary movement and incorporates ideas about dynamic online limb control based on prior expectations about the efferent and afferent consequences of a planned movement. The model considers the relationship between movement speed and accuracy, and how performers adjust their trial-to-trial aiming behavior to find a safe, but fast, zone for movement execution. The model also outlines how the energy and safety costs associated with different movement outcomes contribute to movement planning processes and the control of aiming trajectories. Our theoretical position highlights the importance of advance knowledge about the sensory information that will be available for online control and the need to develop a robust internal representation of expected sensory consequences. We outline how early practice contributes to optimizing strategic planning to avoid worst-case outcomes associated with inherent neural-motor variability. Our model considers the role of both motor development and motor learning in refining feed-forward and online control. The model reconciles procedural and representational accounts of the specificity-of-learning phenomenon. Finally, we examine the breakdown of perceptual-motor precision in several special populations (i.e., Down syndrome, Williams syndrome, autism spectrum disorder, normal aging) within the framework of a multiple-process approach to goal-directed aiming.
\end{abstract}

Keywords: motor control, visual feedback, speed-accuracy, optimizing performance, motor learning

In 1899 R. S. Woodworth published an important monograph on the accuracy of voluntary movement. Although the article made a number of unique contributions to one's understanding of perception and motor control, the most lasting impact of the monograph is associated with Woodworth's two-component model of limb control. This model holds that goal-directed reaching and aiming movements are composed of two distinct phases. Initially, there is

Digby Elliott, School of Sport and Exercise Sciences, Liverpool John Moores University, Liverpool, England, and Department of Kinesiology, McMaster University, Hamilton, Canada; Steve Hansen, School of Sport and Exercise Sciences, Liverpool John Moores University, and Department of Physical Education and Kinesiology, Brock University, St. Catharines, Canada; Lawrence E. M. Grierson, Toronto Rehabilitation Institute, Toronto, Canada; James Lyons, Department of Kinesiology, McMaster University; Simon J. Bennett and Spencer J. Hayes, School of Sport and Exercise Sciences, Liverpool John Moores University.

Preparation of this article was supported by the Natural Sciences and Engineering Research Council of Canada and the Research Institute for Sport and Exercise Sciences, Liverpool John Moores University.

Correspondence concerning this article should be addressed to Digby Elliott, Department of Kinesiology, McMaster University, Hamilton, Ontario L8S 4K1, Canada. E-mail: elliott@mcmaster.ca a ballistic, preprogrammed phase (i.e., initial adjustment) that brings the limb to the vicinity of the target. This distance-covering portion of the movement is followed by a homing phase (i.e., current control). During this second phase, visual and proprioceptive feedback is used to reduce any discrepancy between the limb and the target position. Slower movements were deemed to be more accurate than rapid movements because they allow more time for feedback-based error reduction during the homing phase.

Over the next 100 years, Woodworth's (1899) two-component model of limb control provided the basis for a number of other dual-process models of limb control. Most of these models were developed to explain speed-accuracy relations in goal-directed aiming (e.g., Fitts, 1954; Fitts \& Peterson, 1964). As such, the two-component model continued to make a significant contribution to the motor control literature (see Elliott, Helsen, \& Chua, 2001). However, whereas it is beyond doubt that both prior planning and online control have important roles to play in the speed and precision of goal-directed aiming, over the last decade it has become increasingly clear that Woodworth's simple twocomponent model, and its descendants, fail to fully capture the flexibility and sophistication of skilled limb control.

In this article, we review the contribution of Woodworth's two-component model of limb control from 1899 until the publi- 
cation of Meyer, Abrams, Kornblum, Wright, and Smith's (1988) influential optimized submovement model. Building on Meyer et al.'s version of the two-component model, we develop a description of limb control that considers not only the time and accuracy constraints associated with the particular motor task but also the strategic approach of the performer. This approach depends on a number of variables including prior knowledge about the specific sensory information that will be available for online limb control and the energy requirements of the task. Our model also takes into consideration the past and immediate practice history of the performer and the temporal, energy, and safety costs associated with different types of errors. In this first portion of the review, we describe how expectations about planning error and neural-motor noise that are present prior to movement initiation determine both the central tendency and variability of the endpoint of the so-called ballistic phase of an aiming movement. Subsequently, these endpoints define the type and timing of discrete corrections that may be required to achieve the target position. Accordingly, the first section of the article addresses the complex independency between the first and second phase of goal-directed aiming movements.

The second section of this article tackles the issue of whether the first phase of an aiming movement is really ballistic. On the basis of recent work in which novel kinematic methods were introduced to examine the presence and effectiveness of feedback-based processes (e.g., Khan et al., 2006), we make the argument that some aspects of the initial impulse (i.e., Woodworth's, 1899, initial adjustment) are subject to online regulation. Following the presentation of evidence for early online limb control, we present a model of limb control that posits two distinct forms of online regulation. In keeping with Woodworth (1899), we acknowledge the importance of a discrete form of control late in the movement trajectory that takes into consideration the relative positions of the limb and the target. We refer to this late discrete type of regulation as limb-target control. In addition, we posit an earlier form of limb control for which target information is not important (cf. Elliott et al., 2001). This graded, or continuous, form of control is based on a comparison of perceived velocity and direction of the limb to an internal model of sensory expectations. This form of control can occur very early in the movement, long before the limb approaches the target position. Although it begins early, it can operate throughout the whole duration of the primary submovement or initial impulse. Thus we refer to this corrective process as impulse control. Because the internal model of the expected sensory consequences of the movement is formed at the time of movement planning, impulse control is highly dependent on the performer's expectations about the availability and salience of different types of feedback. In providing the foundation for this model, we review a number of studies designed to dissociate these two forms of control in the same aiming movement.

In the third section of this article, we turn our attention to motor learning and the development of optimal limb control. In particular we describe how our new theoretical position can reconcile competing explanations of the specificity-of-learning phenomenon. We speculate about the impact of specific types of practice on movement planning, continuous control, and discrete control. Our contention is that the specificity-of-learning phenomenon depends on both impulse and limb-target control. We posit that motor learning findings consistent with a representational view of specificity of learning are associated with impulse control, whereas a procedural account of specificity of learning best describes the changes that occur in limb-target control. We also speculate that some of the same transitions in limb control associated with motor learning may also occur in normal motor development.

Finally, we draw on research conducted with several special populations to highlight how the breakdown of specific control processes leads to perceptual-motor slowing or inaccuracy in limb control. In this section, we demonstrate how the hypothesized visual-motor processes associated with our new model of limb control can help one understand various unique patterns of suboptimal performance. As well, we reflect on how specific movement pathologies can be used as a model for understanding typical limb control.

Our overall approach is to extend upon Elliott et al.'s (2001) Psychological Bulletin article, which provided an overview of the developments in the two-component model through the 20th century. In keeping with Woodworth's (1899) influential contribution, we continue to hold that there are two primary phases to most aiming movements (see Elliott et al., 2001). However, in this review we draw on research conducted over the last decade to show how the nature of the first phase (i.e., the initial impulse) depends on several processes related to prior planning and the state of the system (cf. Elliott et al., 2001). These processes and states include the development of the initial action plan, noise and expected noise in the neural-motor system, and the online evaluation of both efferent and afferent information against motor and sensory representations of what was expected at the time of movement planning. Thus, whereas there may be only two components to a goal-directed aiming movement (Elliott et al., 2001; Woodworth, 1899), recent work shows that a number of interrelated and complementary limb control processes contribute to what Woodworth termed the "initial adjustment" (i.e., impulse control). The effectiveness of early error-reducing processes impacts both the need for and the type of late "current control" (Woodworth, 1899; i.e., limb-target control).

\section{The Two-Component Model Then and Now}

\section{Woodworth's Original Formulation}

Woodworth (1899) based his two-component model on the outcome of a series of experiments that involved timed aiming movements in one dimension. Participants made sliding movements on paper with a pencil between two lines, a fixed distance apart. The paper was secured to a drum that rotated at a constant velocity. Thus the procedure provided both a record of endpoint aiming error and a time-based record to the entire movement. Participants were required to keep pace with a metronome. This method allowed Woodworth to vary movement time. In order for him to evaluate the contribution of visual feedback to movement accuracy, the protocol involved participants performing these aiming movements with their eyes open and closed.

Woodworth (1899) found that the initial phase of most aiming movements was rapid and relatively stereotyped. However, as the pencil approached the target line, the movement slowed, and the time-displacement profile often had discontinuities. These discontinuities were taken to reflect modifications to the limb's trajectory. This latter part of the movement trajectory was also associated with greater trial-to-trial variability. These two distinct 
portions of the movement were termed the initial adjustment and the current control phase, respectively.

In keeping with the idea that it takes time to process visual feedback, Woodworth (1899) found that no current control phases were observed in most rapid movements. As well, when the metronome speed was high, there were no accuracy differences between eyes-open and eyes-closed conditions, indicating that it was visual feedback processing during the current control phase that determined movement accuracy. In accordance with eyesopen and eyes-closed differences in movement accuracy, Woodworth estimated the visual processing time to be approximately $450 \mathrm{~ms}$. However, because he used reciprocal aiming movements, the durations of individual aiming attempts included not only the time spent moving toward the target but also the time spent reversing the movement. Thus the corrected visual processing time in this study is probably closer to $225 \mathrm{~ms}$ (Carlton, 1992). This latter time is consistent with an estimate made almost 70 years later by Keele and Posner (1968) using a discrete aiming procedure.

\section{Variations on the Two-Component Model}

Building on work by Crossman and Goodeve (1983) in the early 1960s, Keele (1968) presented a framework for understanding speed-accuracy relations in goal-directed aiming that came to be known as the iterative correction model. The model formalized Woodworth's (1899) ideas about the "initial adjustment" with the concept of a motor program defined by Keele as "a set of muscle commands that are structured before a movement sequence begins, and that allow the entire sequence to be carried out uninfluenced by peripheral feedback" (Keele, 1968, p. 387).

Keele's (1968) theoretical goal was to provide a process-based explanation of Fitts's Law (Fitts, 1954; Fitts \& Peterson, 1964). Fitts's Law was, and continues to be, a powerful description of the relationship between movement time and the accuracy requirements for both discrete (Fitts \& Peterson, 1964) and reciprocal (Fitts, 1954) goal-directed aiming movements. The Fitts equation is

$$
\text { Movement Time }=a+b\left[\log _{2}(2 A / W)\right],
$$

where $A$ equals movement amplitude, $W$ equals target width, and $a$ and $b$ are empirically derived constants that depend on the characteristics of the performer and the specific task environment.

Like Woodworth (1899), Keele (1968) proposed that the initial portion of an aiming movement was programmed and thus continued uncorrected until there was time for visual and proprioceptive feedback loops to operate. In line with his own empirical estimate of visual processing time (Keele \& Posner, 1968), Keele proposed that movements unfold for approximately $200 \mathrm{~ms}$, after which a second motor program is engaged to correct error associated with execution of the first program. This process of intermittent error correction continues until the final target position is achieved. The idea was that when accuracy constraints are high (e.g., large amplitude movements to very small targets; see Fitts, 1954), multiple corrective programs would be required. This situation would result in long movement times. When accuracy demands were low, movement times would be shorter because fewer or, in the extreme case, no corrections are required. Consistent with Woodworth's ideas, limb control involved both open- and closed-loop contributions. However, high index-of-difficulty movements involved multiple rather than a single corrective process. As well, in the iterative correction model, each corrective submovement was said to be ballistic in nature rather than a homing movement that is continually driven by visual feedback.

More in line with the two-component model of limb control was the single-correction model forwarded by Beggs and Howarth $(1970,1972)$ in the early 1970s. Similar to Woodworth's (1899), this model posited a single corrective process. However, the major constraint was the time required for the single correction to be realized. The single correction was thought to occur at a fixed interval before the end of the movement. From their empirical work, Beggs and Howarth (1972) estimated this time to be approximately $290 \mathrm{~ms}$. The idea was that if more time was taken to perform the aiming movement (i.e., longer movement times), then the limb would be closer to the target when the single correction occurred. Corrections occurring in spatial proximity to the target would be more precise, thus explaining the relationship between movement speed and endpoint accuracy.

Although both the iterative correction model and the singlecorrection model were influential for a number of years after their publication, the increased access of movement scientists to highspeed digitizing and optoelectric systems soon made it apparent that actual aiming trajectories were not fully consistent with the idea of either multiple ballistic corrections throughout the trajectory or a single correction at some fixed interval prior to movement termination. In fact, the nature of the discontinuities in velocity and acceleration profiles near the spatial termination of typical aiming movements most resembled the type of control associated with Woodworth's (1899) two-component model (e.g., Chua \& Elliott, 1993). Although even Keele (1981) acknowledged the shortcomings associated with the iterative correction model, the model did set the stage for an influential model of speed-accuracy relationships introduced by Meyer et al. (1988) a number of years later. Meyer et al.'s optimized submovement model was also based on some interesting ideas about open-loop control first introduced by Richard A. Schmidt and his students in the late 1970s (Schmidt, Zelaznik, \& Frank, 1978; Schmidt, Zelaznik, Hawkins, Frank, \& Quinn, 1979).

Unlike Woodworth's (1899) dual-process model of limb control, Schmidt et al. (1978, 1979) suggested that the relationship between movement speed and movement accuracy was independent of feedback utilization for error reduction. The notion was that fast movements, or movements of a greater amplitude, required greater muscular force than slower, smaller amplitude movements. In the manner of Weber's Law in psychophysics, Schmidt et al. (1979) proposed that variability in force production would increase proportionally with the absolute magnitude of the forces required to accelerate and decelerate the limb. Thus more trial-to-trial force variability would result in greater spatial variability in the movement endpoint or, in other words, a greater effective target width (i.e., variable error in movement amplitude). Although Wallace and Newell (1983) demonstrated that the absolute force requirements of a movement were the main determinant of endpoint consistency when vision was not available, it is also the case that with vision the relationship between force and endpoint error begins to break down for movement times of more than $200 \mathrm{~ms}$ (Schmidt et al., 1979). Presumably this outcome occurs 
because visual feedback for error reduction begins to have an impact on movements of this duration.

For the last 20 years, the optimized submovement model (Meyer et al., 1988) has been the most influential explanation of Fitts's Law. The model combines elements of both the iterative correction model (Keele, 1968) and Schmidt et al.'s (1979) impulse variability model of limb control. The optimized submovement model holds that inherent noise in the motor system affects movement execution and therefore the variability of primary movement endpoints. Because noise has stochastic properties, there will be a normal distribution of primary movement endpoints centered at the middle of the target when a performer attempts to produce the same target aiming movement over a series of trials. The spread of this distribution increases with the force requirements of the primary movement. Fast movements require more force than slow movements of the same amplitude. Therefore the standard deviation of movement endpoints (i.e., effective target width) will be greater for fast movements than slow movements.

When preparing goal-directed aiming movements, the performer must strike a compromise between fast (forceful) movements that are associated with greater endpoint variability and movements that are, on average, more precise but take a longer time to complete. For a given movement amplitude, the exact compromise will depend on the size of the target. This dependency occurs because for fast movements to small targets, the majority of the primary movement endpoints would fall outside the target boundaries. Thus a corrective submovement will be needed to achieve the target area. Corrective submovements take time to complete and add to the overall movement time. As the name of the model suggests, the performer selects a movement time goal that optimizes the speed of the primary movement such that a reasonable proportion of trials will not require a time-consuming correction. However, corrections are unavoidable over a number of trials because of the stochastic properties of neural-motor noise. Moreover, because endpoints of corrective submovements are also normally distributed, there will be some trials in which they must be corrected as well. That said, if movements are prepared optimally, the proportion of such trials should be quite small (Meyer, Smith, Kornblum, Abrams, \& Wright, 1990).

\section{Empirical Ground Work for a Multiple-Process Model}

\section{Optimal Outcomes Revisited}

The model of Meyer et al. (1988) does an excellent job of explaining the relationship between movement time and the accuracy constraints associated with movement amplitude and target size in goal-directed aiming (i.e., Fitts's Law). However, at least one tenet of the optimized submovement model is not consistent with kinematic data acquired in a number of target-aiming studies in which the limb must physically move between two positions in space (e.g., Chua \& Elliott, 1993; Elliott, Hansen, Mendoza, \& Tremblay, 2004; Engelbrecht, Berthier, \& O'Sullivan, 2003). That is, the center of the endpoint distribution of primary movements is seldom the middle of the target. Rather, the primary movement generally undershoots the target with a very low proportion of target overshoots. As well, Worringham (1991) has shown that undershooting happens to a greater extent for rapid, large amplitude movements with greater endpoint variability. This scaling of primary movement endpoints to movement amplitude, speed, and variability was found for both three-dimensional aiming movements and one-dimensional wrist movements.

Elliott et al. (2004) suggested that general undershooting occurs because not all errors are equal. Specifically, target overshoots are more costly than target undershoots because to correct a target overshoot, the limb must travel further and also overcome the inertia of a zero velocity situation at the point of reversal. Thus, although target hits are obviously ideal, overshoots are more costly than undershoots because they require more time and energy to correct (Elliott, Hansen, \& Grierson, 2009; Elliott et al., 2004). It is also the case that for many real-world reaching tasks, there are safety and other advantages associated with undershooting. For example, when reaching for a pot on the stove, it is better for the limb to initially undershoot the pot handle than end up in hot water. Indeed, there are many situations in which overshooting can lead to spilling or a severe hand injury.

In a study designed to examine the impact of practice on target undershooting, Elliott et al. (2004) demonstrated that central tendency of the primary movement distributions was tied to the variability of those distributions. Early in practice (i.e., Day 1), participants undershot the center of the target to a greater extent than later in practice (i.e., Day 4). This outcome occurred because early in practice there was more trial-to-trial variability in primary movement endpoints. As participants became more proficient at the aiming, movement variability decreased, and thus they were able to prepare initial submovements that came closer to the center of the target. This shift in central tendency following practice was also reported by Pratt and Abrams (1996) and Khan, Franks, and Goodman (1998). In the Elliott et al. study, what remained unchanged was the small percentage of target overshoots that needed correction by a reversal in movement direction. These percentages remained approximately constant at less than $10 \%$ (see Figure 1). Thus, although the mean of the distribution and the near tail of the distribution moved toward the center of the target with practice, the far tail of the distribution was invariant. Presumably this outcome occurred because participants were unwilling to accept an overshoot rate of greater than $10 \%$. These findings were fundamental in formulating a model of speed and energy optimization (Elliott et al., 2004), which posited that the degree of undershooting of the primary submovement depends on the temporal and energy costs associated with target overshooting.

To examine this aspect of the model, Lyons, Hansen, Hurding, and Elliott (2006) had participants perform rapid aiming movements from a central home position to one of two targets. In one situation, the target-aiming apparatus was placed flat on a tabletop so that the movements were made either away from or toward the body. In a second situation, the apparatus was positioned vertically so that aiming movements of the same distance were made either up or down. Lyons et al. predicted undershooting with the primary submovement in all situations. As well, they expected greater undershooting for downward aiming movements. Consistent with the model, this outcome is exactly what they found. The idea is that when aiming downward, overshooting the target position with the primary submovement is more costly (i.e., even more so than for a horizontal movement). This outcome occurs because the corrective submovement is made against gravity, and that type of correction requires more time and energy depending partly on the mass of the limb. Also consistent with the Elliott et al. optimiza- 
tion of speed and energy model was the finding that the degree of undershooting in the four directions was scaled to the withinparticipant spatial variability in primary movement endpoints (see Figure 2; see also Worringham, 1991). Once again, the idea is that for a given aiming task, the performer must discover a distribution of primary movement endpoints that minimizes the proportion of aiming trials that overshoot the far target boundary.

As mentioned earlier, Elliott et al. (2004) and others (e.g., Khan et al., 1998) had found that, with practice, there is a decrease in the standard deviation of the primary movement endpoints. This decrease in variability allows the performer to "sneak up" on the target as learning progresses without increasing the proportion of primary movement overshoots. The question is, how is this reduction in endpoint variability achieved? One possibility is that, with practice, the performer becomes more precise at specifying the magnitude and duration of the muscular forces required to accelerate and decelerate the limb (Khan et al., 1998). The improvement in the precision of force generation certainly seems to occur when response-produced feedback is available. For example, in their 2004 work, Elliott et al. found that participants made trial-to-trial adjustments to their aims such that primary submovement error on trial $N$ was a robust predictor of error on trial $N+1$ (see also Cheng, Luis, \& Tremblay, 2008). Specifically, two consecutive undershoots occurred only rarely, and two overshoots in a row never occurred. The idea is that the performer uses information

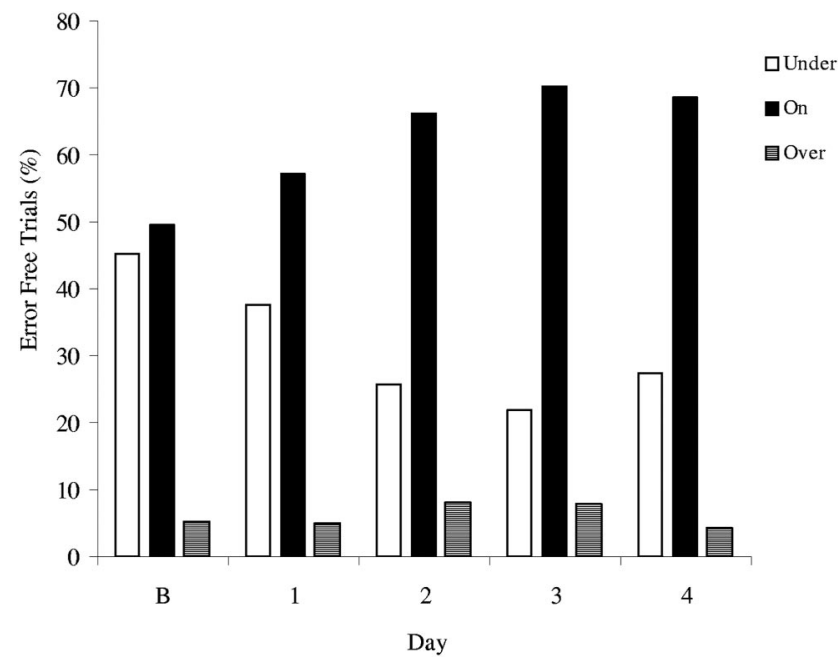

Figure 1. The proportion of error-free trials in which the primary submovement undershot, hit, and overshot the target. The mean proportions are broken down by day of practice. Baseline (B) data were collected without participants receiving movement time feedback. Each day, participants received movement time feedback in order to improve their movement time performance. In spite of a $25 \%$ reduction in movement time over the 4 days of practice, participants exhibited a greater degree of accuracy with their primary submovements. Although participants exhibited fewer undershoots and more hits with practice, notice that the proportion of overshoots remained approximately constant at less than $10 \%$. Adapted from "Learning to Optimize Speed, Accuracy, and Energy Expenditure: A Framework for Understanding Speed-Accuracy Relations in GoalDirected Aiming," by D. Elliott, S. Hansen, J. Mendoza, and L. Tremblay, 2004, Journal of Motor Behavior, 36, p. 347. Copyright 2004 by Heldref Publications.

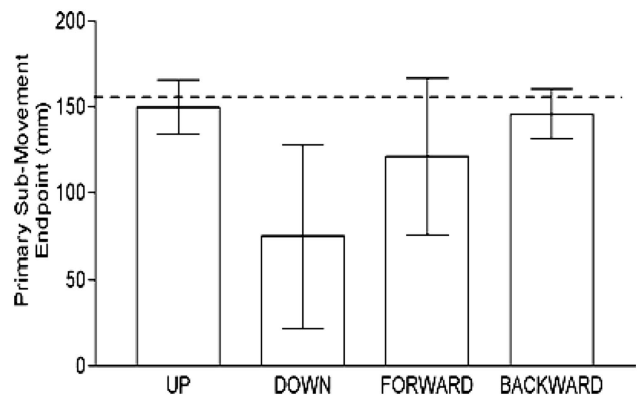

Figure 2. Amplitude of the primary submovement toward a 16-cm target as a function of movement direction. The error bars represent withinparticipant standard deviations of the primary movement endpoints. Although there was generally undershooting in all four conditions, observe that the undershooting was greatest for downward aiming movements in which corrections must be made against gravity. Notice also that the degree of undershooting in the four conditions scales approximately to the withinparticipant variability of the primary movement endpoints. This strategy would have the effect of keeping the number of overshoots reasonably constant and to a minimum across all conditions. From "Optimizing Rapid Aiming Behaviour: Movement Kinematics Depend on the Cost of Corrective Modifications," by J. Lyons, S. Hansen, S. Hurding, and D. Elliott, 2006, Experimental Brain Research, 174, p. 99. Copyright 2006 by Springer-Verlag.

from the previous trial to make the force-time adjustments necessary to reduce error. These sorts of trial-to-trial changes in behavior also occur in serial reaction time tasks as participants attempt to discover how fast they can respond without making an error (e.g., Rabbitt, 1981; for a neural account of changes in strategic behavior, see Bogacz, Wagenmakers, Forstmann, \& Nieuwenhuis, 2010).

Although more precise movement planning accounts for some of the reduction in aiming variability with practice, other processes are also involved. For a number of years, it has been clear that the primary submovement (i.e., the so-called ballistic component) is not as predetermined as previously thought. In the next section of this article, we review the evidence for early, continuous online control before presenting a model of goal-directed aiming that has as its main feature two distinct types of feedback-based regulation (i.e., impulse control and limb-target control).

\section{Early Online Control}

Since the influential work of Keele and Posner (1968), a number of other investigators have found that visual feedback can be used more rapidly than 190-260 ms. Estimates of visual processing time ranged from $140 \mathrm{~ms}$ (Elliott \& Allard, 1985) to less than 110 ms (Bard, Hay, \& Fleury, 1985; Zelaznik, Hawkins, \& Kisselbu-

\footnotetext{
${ }^{1}$ Target undershooting occurs to an even greater extent when visual feedback is eliminated or degraded during movement execution (e.g., Elliott \& Lee, 1995). Surprisingly, even in tasks like foul and jump shot shooting in basketball, where overshoot errors are preferable to undershoot errors (i.e., because of the backboard), skilled performers tend to undershoot the target to a greater extent when vision of the target and limbs is degraded during execution (Ferraz de Oliveira, Huys, Oudejans, van de Langenberg, \& Beek, 2007; Ferraz de Oliveira, Oudejans, \& Beek, 2006).
} 
rgh, 1983; see also Carlton, 1981, 1992). An important difference between Keele and Posner's protocol and experiments conducted in the 1980s (e.g., Elliott \& Allard, 1985; Zelaznik et al., 1983) is that in the latter participants knew in advance whether vision would be available on a given trial (i.e., blocked vs. random manipulation of vision). This prior knowledge allowed participants to prepare their movements differently.

Strategic differences between vision and no-vision trials are often reflected in the kinematic characteristics of the movement trajectory. For example, Hansen, Glazebrook, Anson, Weeks, and Elliott (2006) demonstrated that when performers were cued in advance about the specific target location for an upcoming trial and that vision would be available, they exhibited asymmetric velocity profiles in which more absolute and proportional time was spent after peak velocity than before peak velocity. This type of velocity profile is typically associated with the late utilization of visual feedback for limb control (Elliott et al., 2001). When they were uncertain about the upcoming target location or availability of vision, the limb trajectory resembled aiming without vision. Specifically, the movement trajectory was more symmetric. Also, people took more time to prepare their movements under no-vision conditions and in situations in which there was uncertainty about whether vision would be eliminated on movement initiation (i.e., longer reaction time interval; Elliott \& Allard, 1985; Hansen et al., 2006). Thus it appears that movement planning and online visual feedback utilization go hand in hand (cf. Whitwell, Lambert, \& Goodale, 2008).

It is interesting that with practice, under full vision conditions, limb trajectories get faster and more asymmetric (Elliott, Chua, Pollock, \& Lyons, 1995; Khan \& Franks, 2000). This improvement occurs because the performer achieves higher peak velocities earlier in the movement. This type of execution reflects an effective feedback-based strategy because it gets the limb closer to the target in less time. For the same overall movement time, this provides more time for feedback utilization with the limb in the area of the target. Once again, the performer learns to optimize movement speed to take full advantage of error-reducing online processes. With practice, the performer gets better at using visual response-associated feedback rapidly for limb control.

Adult performers show distinct accuracy advantages when vision is available, even for very rapid movements, and these advantages are often accompanied by a proportionally longer deceleration phase. However, accuracy advantages associated with vision are often independent of the number of discontinuities in the latter part of the aiming trajectory (e.g., Elliott, Binsted, \& Heath, 1999; Elliott, Carson, Goodman, \& Chua, 1991; Meyer et al., 1988; cf. Khan \& Franks, 2000). Moreover, in a number of studies, Proteau and colleagues (e.g., Mackrous \& Proteau, 2007; Proteau, 2005; Proteau \& Masson, 1997) have reported that manipulating vision affects movement accuracy under conditions in which discrete corrections to the trajectory are either completely absent or not possible. In one compelling study, Proteau and Masson (1997) had participants make computer-based aiming movements in which a cursor was moved across a computer screen to a small target. At movement initiation the experimenters sometimes introduced a perturbation to the background on the computer screen. Specifically, texture elements on the computer screen could begin to move either in the same direction as the cursor or in the opposite direction. This perturbation creates a misperception of the velocity of the cursor (see also Smeets \& Brenner, 1995; Whitney, Westwood, \& Goodale, 2003). When the background elements were moved in the opposite direction to the cursor, participants perceived the cursor to be moving more rapidly than had been planned, and they terminated their movement earlier. The opposite was true when the background was moving in the same direction as the cursor. Presumably, participants were able to regulate the velocity of their movement to adjust for the misperception associated with the moving background. In this study, Proteau and Masson examined only where the primary submovement ended, and thus the online regulation associated with misperceived velocity occurred during the so-called ballistic portion of limb control (i.e., impulse control).

Early online adjustments to movement direction have also been reported. For example, using a virtual aiming setup in which a small sphere represented the position of the fingertip, Saunders and Knill (2003) were able to introduce small perturbations to the position of the limb during the aiming movement. The perturbations were perpendicular to the primary direction of the movement (i.e., a directional perturbation), and they were introduced at either $25 \%$ or $50 \%$ of the overall movement extent. Even though participants were unaware of the perturbation, they made smooth adjustments to their limb trajectories to compensate for the change in finger position. Noticeable changes in the limb trajectories were apparent after approximately $160 \mathrm{~ms}$ and occurred as early as $60 \%$ of the movement extent. Thus for the perturbations introduced at $25 \%$ of the trajectory, a noticeable adjustment would typically begin somewhere between peak velocity and peak deceleration, long before the portion of the trajectory associated with late discrete target control.

Cressman, Franks, Enns, and Chua (2006) found similar automatic trajectory adjustments to changes in target position. In their study, the adjustments occurred in as little as $150 \mathrm{~ms}$ and were again unconscious. Unintentional shifts in the aiming trajectory could not be elicited by a change in target color. This latter finding is consistent with the notion that there are separate visual pathways within the brain that are associated with object identification and recognition and the visual control of movement (e.g., Milner \& Goodale, 1995).

In another series of experiments designed to examine rapid limb control, Hansen, Elliott, and Tremblay (2007) used a prism either to introduce or to remove a 25-diopter lateral displacement at, or shortly after, movement onset. The introduction of the prism had the effect of shifting the target and hand approximately $15^{\circ}$ so that visual feedback was inconsistent with what was expected. Under these conditions, participants very rapidly adjusted their aiming trajectories to conform to the new visual information. Once again the adjustments to the limb trajectory were more continuous than discrete, suggesting a graded feedback-based response to the unfolding movement trajectory rather than the implementation of a single corrective submovement (see also Cressman et al., 2006). These sorts of graded adjustments to the primary submovement following perturbations to perceived movement velocity (e.g., Proteau \& Masson, 1997) and direction (e.g., Hansen et al., 2007; Saunders \& Knill, 2003) are consistent with the large reductions in trial-to-trial spatial variability one normally sees between peak deceleration and the end of the movement when full visual feedback is available (e.g., Hansen, Elliott, \& Khan, 2008; Khan, Elliott, Coull, Chua, \& Lyons, 2002; Khan et al., 2003; see Khan 
et al., 2006, for a review). Moreover, they are consistent with the finding that the provision of visual feedback, as early as peak velocity, decreases endpoint aiming error and variability (e.g., Heath, 2005). Thus the initial impulse or primary submovement does not appear to be as ballistic as previously thought (e.g., Elliott et al., 2001; Meyer et al., 1988; Woodworth, 1899).

\section{Internal Models and Impulse Control}

Earlier in this article, we made the case that advance knowledge about the afferent information that will be available during movement execution is important for movement planning (Elliott \& Allard, 1985; Hansen et al., 2006; Zelaznik et al., 1983). If prior information about feedback is not available, participants typically prepare for the worst-case scenario (Hansen et al., 2006), or at least plan a response that will minimize negative outcomes. However, advance information is not only needed to specify a number of parameters associated with the magnitude and timing of muscular forces. Indeed, advance information is essential in order that the performer has some idea of what to expect in terms of the sensory consequences of the movement (von Holst, 1954). The notion is that, at the time of movement planning, an efferent copy of the to-beperformed movement, as well as a prediction about the expected sensory consequences of the movement, is stored in the central nervous system for later referencing (e.g., Evarts, 1973; Teuber \& Mishkin, 1954; von Holst, 1954).

In recent years, these representations of the forthcoming action have been referred to as internal models. They are often called forward models because they represent information about what is expected to happen in the unfolding movement (e.g., Davidson \& Wolpert, 2005; Miall \& Wolpert, 1996). The processing details of specific forward models vary somewhat, but there are essentially two processing avenues for these representations to influence online control. One avenue is associated with the monitoring of what goes out of the system. This monitoring process involves a comparison of the efferent commands sent to the muscular apparatus with the efferent copy maintained in the representation. If output of the system (efferent commands) varies from the desired or expected output (efferent copy), the central nervous system has the information necessary to initiate early adjustments to the limb trajectory through a completely feed-forward process. These adjustments are very rapid because they do not require the processing of sensory feedback (e.g., Angel \& Higgins, 1969).

The second avenue for online control involves a comparison of early information from the movement (i.e., both visual and proprioceptive feedback) with an internal representation of the expected sensory consequences of the movement. For instance, visual and proprioceptive information about limb direction (e.g., Hansen et al., 2007; Saunders \& Knill, 2003) and velocity (e.g., Proteau \& Masson, 1997) is compared with a representation of the expected direction and velocity of the limb movement. Despite a processing lag in the pickup of this sensory feedback, the sources of sensory information important for this type of control are available very early in the movement (i.e., long before the limb approaches the target area). If the performer is fixating the target, early visual feedback is acquired via peripheral vision. Peripheral vision is adept at processing movement-related information from the limb and movement environment (Paillard, 1980), and the visual-motor system is even sensitive to this type of dynamic information during a saccade (Desmurget et al., 1999; West, Welsh, \& Pratt, 2009). Once again, if there is a mismatch between what is perceived and what is expected, then error reduction processes are engaged well before the limb is moved to the vicinity of the target. However, unlike the type of discrete target control associated with the two-component model (Elliott et al., 2001; Woodworth, 1899) and the optimized submovement model (Meyer et al., 1988), this early form of online control depends heavily on prior information about the availability of feedback. An individual's need for advance information occurs because the internal model, upon which this type of regulation is based, involves prediction about both motor output and the sensory consequences of that output.

Consistent with evidence presented earlier, under similar task conditions, movement planning on trial $N+1$ depends on the outcome associated with trial $N$ (Elliott et al., 2004; Ghez, Gordon, Ghilardi, \& Sainburg, 1995; Henderson, 1977). This dependency occurs because the representation against which online efferent and afferent information are evaluated changes from trial to trial, with the last few trials (with feedback) being the most important for the calibration of the internal model (Coslett, Buxbaum, \& Schwoebel, 2008; Medina, Jax, \& Coslett, 2009). If the sensory conditions remain unchanged, trial-to-trial adjustments to the internal model will be larger early in practice when the performer is still trying to discover the general force-time parameters that optimize speed, energy expenditure, and accuracy. The internal model against which performance is evaluated will continue to be refined as practice progresses. Because impulse control depends on the efficacy of the internal model, its contribution to online control will increase with practice.

\section{Evidence for Impulse and Target Control}

In a recent series of experiments, Grierson and colleagues (Grierson \& Elliott, 2008, 2009a, 2009b; Grierson, Gonzalez, \& Elliott, 2009) set out to test the hypothesis that there are two types of visual online control associated with manual aiming movements. Following Woodworth (1899; see also Elliott et al., 2001; Meyer et al., 1988), they expected to find a discrete form of control associated with an error reduction process based on the relative spatial position of the limb and the target late in the movement. In addition, it was hypothesized that there would be an earlier form of control that depended on a comparison of the dynamic properties of the unfolding limb movement to the expected sensory consequences. Grierson and Elliott's (2008, 2009a; see also Elliott et al., 2009) research strategy involved the independent manipulation of variables hypothesized to impact one or the other of these online processes in the same experiment.

In their initial study, Grierson and Elliott (2009a) took advantage of visual illusions that have been shown to impact perceived limb velocity (Proteau \& Masson, 1997) and the position of the target (Glazebrook et al., 2005; Mendoza, Elliott, Meegan, Lyons, \& Welsh, 2006). Specifically, a moving background was introduced at movement initiation to provide the illusion that the limb was moving faster or slower than expected. This manipulation was designed to create a mismatch between the perceived velocity of the limb and the expected velocity of the limb and thus prompt an early adjustment to limb velocity (see Proteau \& Masson, 1997). The Müller-Lyer illusion was used to influence the perceived 
position of the target and hence encourage a discrete correction late in the movement. In line with Mendoza et al. (2006), a control target figure was sometimes replaced by a tails-in or tails-out Müller-Lyer figure at movement initiation. When the target is the vertex of the intersecting lines, this configuration has the effect of making the target appear nearer (tails in) or farther away (tails out).

After replicating the findings of Proteau and Masson (1997) and Mendoza et al. (2006) in initial experiments, Grierson and Elliott (2009a) orthogonally manipulated the background and the MüllerLyer endpoints in the same experiment. Thus participants prepared a three-dimensional aiming movement to a control figure in the presence of a stationary background. At movement initiation the aiming context could stay the same, one of two background manipulations could be introduced (i.e., moving the same direction as limb, moving the opposite direction to limb), one of two target manipulations could be introduced (i.e., tails in, tails out), or both a background and a target manipulation could occur.

In keeping with the notion that visual regulation based on limb velocity and target position is associated with separate processes, Grierson and Elliott (2009a) found that the two manipulations had independent and additive effects on endpoint error. Target undershooting was greatest when the tails-in target condition was paired with the background moving in the opposite direction to the limb. Presumably, participants were terminating their movements earlier because both the target appeared nearer and their limb velocities were perceived to be greater than they expected. The opposite was true for the tails-out, same-direction combination. The two illusions had effects that offset each other in the other combinations. Analyses of movement amplitude and spatial variability at different points in the movement indicated that the moving background manipulation influenced the limb trajectory earlier than the Müller-Lyer perturbation. The early influence of the illusion on the limb's trajectory is consistent with the notion that the two illusions affected early impulse and late limb-target control, respectively.

In the second study of the series, Grierson and Elliott (2008) introduced real, rather than illusory, perturbations of limb velocity and target position. As with a number of other studies (e.g., Paulignan, MacKenzie, Marteniuk, \& Jeannerod, 1991; Pélisson, Prablanc, Goodale, \& Jeannerod, 1986), the latter perturbation involved shifting the target position at movement initiation. In this experiment, target position was shifted either toward or away from the home position (e.g., Heath, Hodges, Chua, \& Elliott, 1998). A change in limb velocity was introduced through the use of a stylus rigged with an air compressor such that, shortly after movement initiation, a burst of air was released to propel the limb either forward or backward. Even though both perturbations had overall impacts on aiming performance, which were not independent, of greater importance was the finding that directional adjustments to the limb trajectory following the two perturbations were consistent with predictions. That is, performers adjusted their movement to deal with the velocity perturbation first and made adjustments for the target perturbation later in the movement. This second result was similar to other findings involving a target perturbation (Hansen \& Elliott, 2009; Heath et al., 1998). Overall, the results of this experiment suggest that the corrective processes associated with velocity control and position control begin earlier and later in the movement trajectory, respectively. However, velocity control can continue into the late portions of the movement and thus overlap in time with position control. ${ }^{2}$

As with velocity, there is evidence that movement direction can be amended quickly based on early dynamic information from the limb. For example, Bard et al. (1985) reported that rapid punching movements executed to move through target positions in left and right space could be corrected in as little as $110 \mathrm{~ms}$. In keeping with the notion that the modulation of limb direction occurs early in the trajectory, Bard et al. found that vision of the first $50 \%$ of the movement was more important than vision of the last $50 \%$ (see also Hansen, Cullen, \& Elliott, 2005). This outcome is exactly the opposite of what a number of investigators have found for amplitude control (Carlton, 1981; Chua \& Elliott, 1993), and together these findings are consistent with the idea that direction and amplitude are controlled independently (Gordon, Ghilardi \& Ghez, 1994; Messier \& Kalaska, 1997, 1999; Paillard \& Amblard, 1985). For example, Gordon et al. (1994) had participants aim, using a computer mouse on a graphics tablet, at 16 targets. These targets were positioned at eight locations, arranged in a circle formation, and at two distances from the central home position $(3.2 \mathrm{~cm}$ and $9.6 \mathrm{~cm})$. One of the goals of the study was to explore whether direction and extent (amplitude) are independent parameters of movement. Principal component analyses of the resulting aiming trajectories suggest that this is indeed the case. Specifically, variable error in movement extent was shown to increase in a nonlinear fashion as a function of target distance, whereas variable error in direction remained relatively constant. This result suggests a certain degree of independence of movement extent from movement direction, a situation that the authors attributed to an independent and separate planning of these parameters during the construction of the movement program. One consequence of this independence is the likelihood that the programming of amplitude during the construction of the movement plan is subject to more error than the specification of direction.

Additional evidence for the independence of amplitude and direction control comes from Messier and Kalaska (1999), who, using a similar radial pointing protocol, examined the relationship

\footnotetext{
${ }^{2}$ When a limb movement is physically perturbed, there also appears to be a very rapid adjustment to the perturbation (Grierson \& Elliott, 2008; Grierson et al., 2009). The adjustment is typically status maintaining in nature but biased in the sense that if the participant knows the limb could be pushed either forward or backward, the adjustment usually accommodates the latter. Once again, it appears that the system is biased toward preparing for and adjusting to worst-case scenarios. This type of online control is very rapid because the system does not need to determine the direction of the perturbation. It only needs to detect that a disruption to the movement has occurred. Similar adjustment to limb acceleration can also occur when the visual context for an aiming movement changes at movement initiation (Grierson \& Elliott, 2009a). Once again, although these changes are not sensitive to the specific nature or direction of the visual perturbation, they have the effect of reducing the impact of the worst-case change in the task requirements. For example, when an illusory perturbation was introduced to make the target appear nearer or further away, there was a decrease in peak acceleration in both instances (Grierson \& Elliott, 2009a, 2009b). This adaptation gives the system more time to process the specific nature of the perceived change in target position. Again, the adjustment is rapid because the system needs to determine only that a change has occurred and not the nature of the change (see also Dugas \& Marteniuk, 1989).
} 
between specific kinematic markers and movement amplitude. The results of the study suggest that endpoint distributions are not completely determined by initial kinematics. Rather, the authors suggest that both the direction and extent components of planar aiming movements are determined in parallel as the movement unfolds.

At least with respect to feedback utilization, it may be more appropriate to make a distinction between control based on early limb motion and late limb position relative to the target rather than direction and amplitude. The motion versus position distinction is more appropriate because the overall amplitude of the primary submovement can also depend on early information about perceived velocity (e.g., Proteau \& Masson, 1997). The early limb motion versus late limb position dichotomy also fits nicely with the distinction between egocentric and allocentric frames of reference in the perception and action literature (e.g., Goodale \& Haffenden, 1998; Westwood \& Goodale, 2003; cf. Glover, 2004). Specifically, impulse control based on the absolute coordinates of early limb motion is egocentric in the sense that it is based on an internal, body-based representation of the expected visual consequences of the limb's movement, whereas late control depends on the relative positions of the limb and the target (e.g., an objectobject or allocentric judgment). In this same context, Saunders and Knill (2004) have shown that perturbations to both hand motion and position impact aiming trajectories. As with the findings of Grierson and Elliott (2008, 2009a), they found that motion perturbations had an earlier impact on limb control than changes to hand position. Adjustments based on the latter were apparent only late in the movement when the hand entered central, foveal vision (i.e., target control).

\section{Multiple-Process Model of Limb Control}

In line with Woodworth (1899), our multiple-process model of limb control holds that there are two identifiable components to most goal-directed aiming movements. There is a planned component that gets the limb to the target area, and when time permits, there is a corrective portion of the movement that is engaged to reduce any spatial discrepancy between the limb and target position late in the movement. The effectiveness of this corrective phase of the movement is dependent on vision of the target and the limb. Although limb position can be approximated via efference and proprioception, vision is typically the most useful source of information (Carlton, 1981, 1992; Heath, 2005). Direct visual information about the position of the target is also critical, because memory-based representations of target position deteriorate very rapidly once vision is eliminated (Elliott, 1988; Elliott, Calvert, Jaeger, \& Jones, 1990; Elliott \& Madalena, 1987). In this context it is appropriate to acknowledge that when the eyes are positioned over the target, they also provide extraretinal information based on their position and the efference associated with achieving that position. However, this information is probably used only for limb control when retinal information is degraded (Binsted \& Elliott, 1999).

In contrast to Woodworth's (1899) two-component model (Elliott et al., 2001; Meyer et al., 1988), our multiple-process model holds that the distance-covering phase of the movement is not exclusively ballistic. Our notion is that when a performer is told to move to a target position as quickly and accurately as possible, the performer must determine how fast the movement can be while still hitting the target. The first aiming attempts are designed to determine the degree of variability associated with particular movement velocities. In line with Meyer et al. (1988), endpoint variability increases in a linear fashion with movement velocity. Therefore, each performer must discover the optimal compromise between movement velocity and endpoint variability such that the limb is not positioned outside the target boundaries on a large proportion of the trials. Recall that when the primary submovement undershoots or overshoots the target, a timeconsuming corrective submovement is necessary.

Our multiple-process model of goal-directed aiming holds that, over a number of trials, the performer adjusts the central tendency of primary movement endpoints to scale to the endpoint variability (Worringham, 1991). In contrast to the optimized submovement model (Meyer et al., 1988), we posit that the system takes into consideration the relative temporal and energy costs of undershooting and overshooting when making this determination (Elliott et al., 2004; see also Sparrow \& Newell, 1998). Overshooting will almost always be more costly than undershooting because the limb, or movement device, must travel a greater absolute distance to achieve the target. It must also overcome a zero velocity situation at the point of reversal. Thus the distribution of primary submovement endpoints will generally be centered short of the target (Engelbrecht et al., 2003; Pratt \& Abrams, 1996). The degree of undershooting will depend on variables such as the mass of the effector and whether corrective submovements must be made against gravity (Lyons et al., 2006). Only in artificial situations, in which less force is associated with greater movement distance, will people consistently overshoot the target boundary on the majority of trials. For example, Oliveira, Elliott, and Goodman (2005) constructed a device that used potential energy to assist performers' ballistic aiming movements such that muscular force was required to reduce the amplitude of a targeting movement (i.e., more force translated to less distance). Although participants undershot the target amplitude when unassisted, when using the device, they overshot the target. In both assisted and unassisted conditions, it took more than 75 aiming attempts to reduce this bias to near zero. Thus energy conservation seems to be an important determinant of central tendency even when movement time is not an issue.

Both central tendency and variability are influenced by practice. Following moderate practice in a typical aiming situation, the performer establishes a consistent distribution of primary movement endpoints that optimizes speed, accuracy, and energy expenditure (Elliott et al., 2009). Unless the target is extremely large, the primary submovement will fall outside the target boundary on a fixed proportion of trials. These errors occur because of the stochastic properties associated with neural-motor noise in the system. Target undershoots and the occasional overshoot need to be corrected, and visual information acquired near the end of the primary submovement provides the information necessary for this corrective process to occur. Because people normally fixate the target prior to manual aiming or, under conditions of uncertainty, achieve the fixation shortly after the limb achieves peak acceleration (see Starkes, Helsen, \& Elliott, 2002, for a review), central vision is responsible for this late corrective process that occurs as the limb approaches the target (see Figure 3). The process involves the system computing the difference between limb position and 


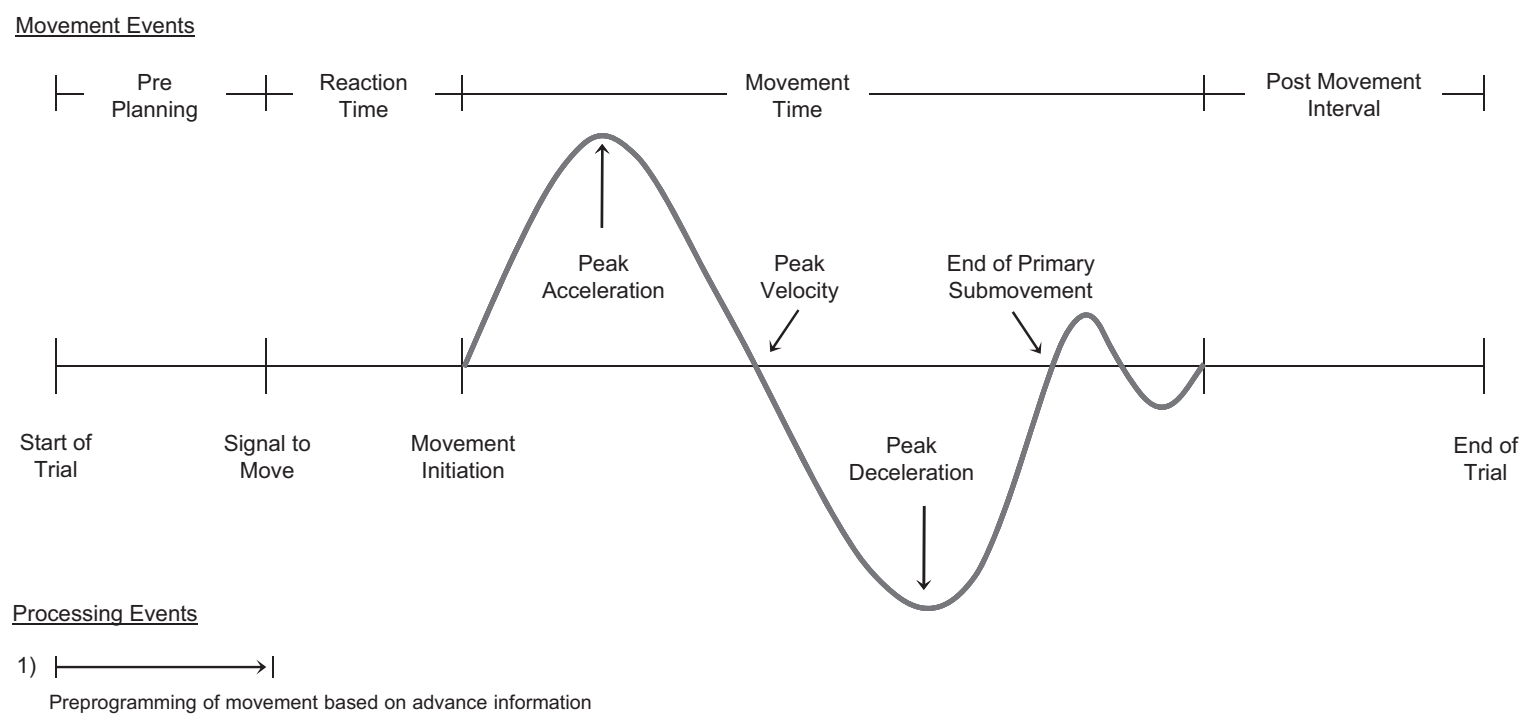

2)

a) Specification of magnitude \& timing of muscular forces; b) Formation of internal representation of expected efference; c) Formation of internal representation of expected sensory consequences

3) $1 \longleftrightarrow \mid$

Comparison of expected efference to produced efference and impulse regulation

4) $1 \longleftrightarrow$

Comparison of perceived sensory consequences to expected sensory consequences and impulse regulation

5) $|\longleftrightarrow|$

Pick-up of information about limb (visual and proprioceptive) and target (visual) position

6) $\underset{\text { Limb-target regulation }}{\longleftrightarrow}$ |

7) $1 \longleftrightarrow \mid$

a) Processing of terminal feedback; b) Refinement of strategy and internal afferent and efferent representations

Figure 3. Hypothesized multiple processing events associated with a single goal-directed movement to a small target for a movement of sufficient duration to engage both online dynamic impulse and target control processes. This specific acceleration profile reflects a trajectory in which the primary submovement undershoots the target and a second acceleration-deceleration is required to extend the amplitude of the movement.

target position and reducing any spatial discrepancy with a discrete corrective submovement. Submovements are reflected in discontinuities in the velocity and acceleration profile (Khan et al., 2006; Walker, Philbin, Worden, \& Smelcer, 1997). With practice these corrective submovements become faster and more efficient (Abrams \& Pratt, 1993). In this respect, they are no different from the primary submovements the corrective submovements are designed to correct.

For a given aiming situation, the performer must discover the temporal and endpoint characteristics of a set of aiming trajectories that, on average, optimize speed, accuracy, and energy expenditure (Todorov, 2004; Trommershäuser, Gepshtein, Maloney, Landy, \& Banks, 2005). However, once that set of trajectories is identified and stabilized, there continues to be improvement in performance. Specifically, participants are able to achieve the same spatial goal with shorter and shorter movement times. One way that these performance changes are achieved is through a reduction in the degree of variability associated with primary submovement endpoints (Elliott et al., 2004; Khan et al., 1998; Worringham, 1991).
It is interesting that the decrease in endpoint variability occurs in conjunction with an increase in the peak velocity of the limb (e.g., Elliott et al., 1995). This latter finding is at odds with the notion that variability scales to the absolute force requirements of the movement (e.g., Schmidt et al., 1979). So, how is this reduction in variability achieved? Some of it may be due to more precise force specification following extended practice. However, because this reduction occurs to a greater extent when vision is available for online control than when it is absent (e.g., Khan et al., 1998), our model holds that some of the reduction in variability is due to online control of the initial movement impulse (i.e., impulse control). That is, the visual-motor system recognizes any discrepancy between what was intended and what was produced and, if time permits, adjusts the characteristics of the early trajectory.

In keeping with the notion of internal forward models of limb control (e.g., Miall \& Wolpert, 1996; Wolpert \& Flanagan, 2001), we posit that at the time of movement planning both motor and sensory representations of the expected consequences of the movement are formed. The motor representation, which has been tradi- 
tionally referred to as an efferent copy (von Holst, 1954), provides a reference against which early neural outflow can be compared and, if necessary, corrected (e.g., Angel \& Higgins, 1969). More important from our perspective, an internal model of the expected sensory consequences of the movement provides a reference against which early visual and proprioceptive feedback can be compared (e.g., Desmurget \& Grafton, 2000). A number of studies (e.g., Ghez et al., 1995; Grierson \& Elliott, 2008, 2009a, 2009b; Hansen et al., 2007; Proteau, Roujoula, \& Messier, 2009) suggest that early information about the velocity and direction of the limb movement are important for this type of control. Impulse control is more continuous in nature than limb-target control (Saunders \& Knill, 2003, 2004) and in this respect involves graded adjustments to the muscular forces that accelerate or decelerate the limb. This control system takes advantage of the sensitivity of the peripheral retina for processing motion associated with the expected sensory consequences of the movement (Paillard, 1980, 1996; Paillard \& Amblard, 1985). ${ }^{3}$

Because impulse control is based on a comparison of perceived and expected efference and afference, it is extremely dependent on advance information about the upcoming task requirements and the sources of information that will be available (Hansen et al., 2006). Thus, for example, the system does not prepare for the visual sensory consequences of an action if at the time of movement planning the performer is uncertain whether vision will be eliminated upon movement initiation (e.g., Keele \& Posner's, 2006, random vs. Zelaznik et al.'s, 1983, blocked vision protocol). When there is doubt about what afferent information is available, performers prepare for the worst-case scenario. In the above example, they would prepare a movement with the expectation that vision will not be available. According to our model, this situation precludes any possibility of early visual control. However, the discrete system still takes advantage of the late information about the position of the limb and target if that information is available (Hansen et al., 2006).

In summary, there are at least three types of online regulation possible when advance information is available about sensory feedback. These include (a) early efferent control based on a comparison of efferent copy to efferent outflow, (b) early and continuing afferent control based on a comparison of the early dynamic properties of the limb movement (visual and proprioceptive) to the expected sensory consequences, and (c) late visual control based on a comparison of limb and target position as the limb enters central vision. Of course these three online evaluation and error reduction processes also have an impact on preparation of the next movement. Thus with practice the internal model (both motor and sensory) is refined from trial to trial so that for most aiming attempts there will be less discrepancy between what was expected and what was actually realized. Between-trial refinement of the internal model will also depend on any type of explicit feedback that may be available, such as knowledge of results about movement time and aiming error (Elliott et al., 2004). Although neural-motor noise will always exist, from both online and terminal feedback, the motor system learns the optimal force-time parameters for the muscular forces designed to achieve the specific reaching or aiming goal on most attempts (even in the corrective process; e.g., Meyer et al., 1988). In Figure 3, we present a time-based schematic of how movement preparation and execution processes might coincide with movement events during a single aiming trial.

\section{Implications for Motor Learning and Development}

Every day a typical adult performs hundreds of reaching movements to positions and objects that are less than a meter from the midline. In spite of this fact, when appropriate feedback is provided about movement speed and accuracy, people can still make tremendous improvements in performance. That is, they become faster, more accurate, or both. For example, Elliott et al. (2004) reported a $20 \%-25 \%$ reduction in movement time for a traditional Fitts's aiming task over 4 days of practice. Similar improvements in performance have been demonstrated for aiming protocols in which accuracy is the primary dependent variable (e.g., Khan et al., 1998; Proteau, Marteniuk, Girouard, \& Dugas, 1987). Although the traditional wisdom has been that, with practice, people progress from a closed-loop to an open-loop mode of control (e.g., Pew, 1966; Schmidt \& McCabe, 1976), the empirical evidence does not support this claim (Elliott \& Jaeger, 1988; Khan et al., 1998; Proteau et al., 1987; Proteau, Marteniuk, \& Lévesque, 1992).

\section{Specificity of Learning}

Compelling evidence against the notion of a closed-loop to open-loop transition with practice was provided by Proteau et al. (1987). In their study, participants practiced a goal-directed aiming movement for either 200 or 2,000 trials. Half the participants in each of the two practice groups had full vision of their limb and the target during aiming, whereas the other half were able to see only the target. After practice, all participants were required to perform in the target-only condition. Proteau et al. found that participants with full vision actually became more dependent on feedback rather than less dependent. Specifically, the performers who had received 2,000 practice trials with vision were compromised to a greater degree when vision was taken away than the participants with only 200 practice trials. This outcome was exactly the opposite of what one would expect if practice leads to the establishment

\footnotetext{
${ }^{3}$ When people reach for a known location in space, they typically check on the position of the hand and then fixate the target position several hundred milliseconds before the movement begins (Starkes et al., 2002). Under conditions of uncertainty, a central fixation point is selected, and the eyes move rapidly to the target when it appears. Subsequently, the hand follows the eye to the target. Helsen and colleagues (Helsen, Elliott, Starkes, \& Ricker, 1998; Helsen, Elliott, Starkes, \& Ricker, 2000) have demonstrated that the eye and hand movements are coordinated so that the eye achieves the target position just after the hand achieves peak acceleration. This pattern of synchronization is ideal for the two types of feedback-based control associated with our multiple-process model of speed-accuracy. Specifically, the eyes are over the target area and in a position to provide foveal information about the relative positions of the limb and the target long before the limb enters the target area. This situation maximizes the opportunity for late discrete visual control (i.e., target control). With the eyes directly over the target area between limb peak acceleration and target acquisition, the position of the eyes is also optimal for the pickup of movement-related visual information about limb velocity and direction (i.e., impulse control). These dynamic sources of feedback are most reliably processed by peripheral vision.
} 
of a stable central representation or motor program to guide the limb without a contribution from movement-based feedback (see the Keele, 1968, definition of a motor program presented earlier; see also Elliott \& Jaeger, 1988). However, if the representation that develops with practice involves expectations about sensory feedback that can be used for online control (e.g., Miall \& Wolpert, 1996), the finding begins to make sense.

On the basis of such results, Proteau et al. (1987, 1992; see Proteau, 1992) formulated the specificity-of-learning hypothesis that held that learning is specific to the sensory conditions under which a motor skill is acquired. For more complex motor skills than manual aiming, the degree of specificity can also depend on the salience of the afferent information that is available for the particular task (e.g., Proteau, Tremblay, \& DeJaeger, 1998; Tremblay \& Proteau, 1998; see also Robin, Toussaint, Blandin, \& Proteau, 2005). However, for goal-directed aiming, other investigators have found results very similar to those of Proteau et al. (e.g., Elliott \& Jaeger, 1988; Elliott et al., 1995; Khan et al., 1998). Insight into the nature of the processes associated with these specificity effects can be gained by examining movement kinematics and how they change as a function of practice.

With practice at manual aiming, participants begin to produce trajectories in which higher peak velocities are achieved earlier in the movement (Elliott et al., 1995; Elliott, Lyons, \& Dyson, 1997; Khan \& Franks, 2000; Khan et al., 1998). This pattern of change reflects the adoption of a strategy that gets the hand to the target area as quickly as possible, leaving more real (and proportional) time for late discrete target control (Elliott et al., 2001). Moreover, late discrete control in the target area also becomes more efficient. Specifically, individual corrective submovements take less time to complete (Abrams \& Pratt, 1993), and they are also more error reducing (Khan et al., 1998). These changes with practice reflect improved feedback-based processes late in the movement associated with reducing the discrepancy between the limb and target position.

As mentioned earlier, with practice, there is also a reduction in the variability associated with primary movement endpoints and an associated switch in these endpoints from more extreme to moderate undershooting (Elliott et al., 2004; Khan et al., 1998; Pratt \& Abrams, 1996). We propose that these changes reflect improved feed-forward and early impulse control processes associated with internal representations of the unfolding action. These processes have their impact earlier in the movement and can therefore impact late limb control as well. Specifically, they can lead to a reduction in the need for late discrete control. This change in control is evidenced by a reduction in the proportion of trials with corrective submovements as practice progresses (Elliott et al., 1995; Khan et al., 1998). As well, Hansen, Tremblay, and Elliott (2005) have shown that, with practice, performers are able to reduce the spatial variability associated with aiming movements earlier in the trajectory.

Although prior information about the sensory information available during movement execution is important to the strategic approaches designed to impact late discrete target control, it is even more essential for impulse control (Hansen et al., 2006). This reliance on prior information occurs because impulse control depends on the performer establishing an internal model of the to-be-performed action that includes expected sensory consequences. If, for example, the performer is uncertain whether vision will be available, the performer can reliably plan only the movement to take advantage of proprioceptive feedback. Our multipleprocess model of limb control holds that differences in prior knowledge about the availability of visual feedback during movement execution can explain differences in the estimates of visual processing time between random feedback (e.g., Keele \& Posner, 1968) and blocked feedback (e.g., Zelaznik et al., 1983) schedules. Specifically under blocked conditions, participants are certain what feedback will be available, and the movement plan and associated forward model are able to include the appropriate expected sensory consequences. Under these conditions, early visual control based on dynamic information about limb velocity and direction is possible (i.e., impulse control). When faced with a random feedback schedule, however, the internal model does not include information about the expected visual consequences of the limb movement and, when vision is available, only late discrete control occurs (i.e., limb-target control). This type of late positional control takes more time to be realized (e.g., Grierson \& Elliott, 2009a, 2009b; Saunders \& Knill, 2004), resulting in longer estimates of visual processing time.

\section{Representational and Procedural Accounts of Specificity}

During the 1990s, there was considerable theoretical debate regarding the processes associated with specificity-of-learning effects in manual aiming. Most of this work was concerned with the availability and use of visual feedback during practice. As described in the previous section, Proteau et al. $(1987,1992)$ forwarded a representational account in which practice led to the development of modality-specific representations. Because these representations provide the basis of future aiming attempts, a change in afferent conditions under which these movements are performed (e.g., the elimination of vision) leads to decrements in performance.

In our multiple-process model of limb control, Proteau's (1987, 1992) representational view of specificity is consistent with the concept of impulse control that is based on a comparison of perceived dynamic feedback and an internal model of the expected sensory consequences. The nature and reliability of the internal model or representation depends on the salience and usefulness of the afferent information available during practice. If, for example, vision is available during practice, the representation will have essential visual-motor components. Any transfer of learning to a retention situation will depend on the usefulness of these components in the new afferent context.

In contrast to Proteau's $(1987,1992)$ representational view, Elliott et al. $(1995,1997)$ posited a procedural view of specificity of learning. They proposed that the degree of positive transfer between practice and retention conditions depended on the degree of similarity between the information-processing procedures required to plan and then regulate the movement during execution. Elliott et al.'s (1995) procedural explanation depended heavily on the strategic approaches that participants adopted to maximize the usefulness of the available information. So, for example, if vision is available only for $400 \mathrm{~ms}$, participants adopt a strategy of getting to the target area very quickly so that they can take advantage of visual feedback about the relative position of the limb and the target late in the movement. If, during retention, vision is available 
for $600 \mathrm{~ms}$, this basic procedure is still useful. However, it is adjusted slightly over the first few retention trials to take advantage of the extra $200 \mathrm{~ms}$ of vision (Elliott et al., 1995). However, these procedures developed over practice would be ineffective if vision was completely eliminated upon movement initiation. This absence of transfer occurs because the aiming strategy and associated information-processing procedures are based on optimizing late visual control.

In retrospect, it seems our procedural view of specificity was consistent with learning to take advantage of visual information for late limb-target control, whereas Proteau's $(1987,1992)$ representational view fits better with ideas about the role of internal forward models in early dynamic control (i.e., impulse control). In this respect, some of the apparent differences between findings that were thought to be consistent with representational and procedural accounts of specificity may have had more to do with methodology than limb control processes per se. For example, in contrast to Elliott and colleagues (e.g., Elliott et al., 1995; see also Khan et al., 1998), Proteau and associates (e.g., Mackrous \& Proteau, 2007; Proteau et al., 2009) have traditionally used a very liberal criterion to define the termination of an aiming movement (i.e., the parsing procedure equates movement termination with the end of the primary submovement). As a consequence, their work has consistently demonstrated vision versus no-vision advantages that reflect online control during the primary submovement or impulse (i.e., the movement was deemed finished before late discrete control was possible). For Elliott and colleagues (e.g., Elliott et al., 1995) and Khan and colleagues (e.g., Khan \& Franks, 2000; Khan et al., 1998), vision versus no-vision advantages also include the opportunity for late discrete control.

In summary, our multiple-process model of limb control appears to be consistent with the motor learning literature associated with specificity of practice. Certainly an important aspect of our model (cf. Beggs \& Howarth, 1970; Keele, 1968; Meyer et al., 1988; Woodworth, 1899) is that it considers how limb control changes, not only with practice but also with prior information about the sensory and motor information that might be available during movement execution.

\section{Motor Development}

Many of the same transitions in limb control that are associated with motor learning may also occur in normal motor development. For example, around 4 months of age, infants begin to display successful reaching behavior that is characterized by a glut of acceleration-deceleration discontinuities (von Hofsten, 1979), high speed (Thelen, Corbetta, \& Spencer, 1996; Wimmers, Savelsbergh, Beek, \& Hopkins, 1998), and a need to finish programmed submovements before beginning new ones (Savelsbergh, von Hofsten, \& Jonsson, 1997). However, although inefficient to start, infants are known to display developmental periods of alternating stable and variable trajectory control (e.g., Konczak, Borutta, Topka, \& Dichgans, 1995; Thelen et al., 1996) along their way to producing more direct and accurate reaches (von Hofsten, 1991). What is important here is that early reaching variability may be indicative of the uncertainty that infants are faced with when trying to integrate newly improved muscle coordination (Konczak et al., 1995) and anticipation processes into their movement con- trol (Konczak \& Dichgans, 1997; Kuhtz-Buschbeck, Stolze, Jöhnk, Boczek-Funcke, \& Illert, 1998).

Similar periods of variable, rapid goal-directed aiming control appear in children at approximately 7 years of age (e.g., Hay, 1978, 1979; Van Braeckel, Butcher, Geuze, Stremmelaar, \& Bourna, 2007; von Hofsten \& Rösblad, 1988). Although the evidence suggests that children have multiple processes available to them prior to age 7 (Barral \& Debû, 2002), it appears that, around this age, they complete aiming movements in a feed-forward manner but also begin to incorporate visual feedback-based forms of control (Hay, 1978, 1979; von Hofsten \& Rösblad, 1988). This transition results in a temporary shift to longer movement times without an immediate improvement in movement accuracy. Moreover, these children further develop their ability to adapt to perturbations to the movement environment (Van Braeckel et al., 2007). Following the incorporation of these complementary processes, more efficient limb control, under both open-loop and closed-loop conditions, begins to emerge over the next 3 years (Ferrel, Bard, \& Fleury, 2001; Pellizzer \& Hauert, 1996).

Although a number of explanations have been forwarded for these qualitative changes in goal-directed behavior (e.g., Chicoine, Lassonde, \& Proteau, 1992; Van Braeckel et al., 2007), post hoc interpretation of this developmental work is consistent with the notion that in infancy, between 5 and 7 years of age, and also between 7 and 10 years, children begin to develop, use, and refine more elaborate internal models for limb control while also learning how to identify movement error and stabilize movement outcomes against various perturbations via feedback processes (Ferrel et al., 2001; Hay, 1979; Konczak \& Dichgans, 1997; Kuhtz-Buschbeck et al., 1998; Thelen et al., 1996). In this context, a series of developmental experiments using procedures similar to those of Grierson and colleagues (Grierson \& Elliott, 2008, 2009a, 2009b; Grierson et al., 2009) that seek to isolate impulse control from limb-target control could prove instructive.

\section{Special Populations and Atypical Visual-Motor Control}

One way to gain insight into the processes associated with goal-directed action is to examine the breakdown in precise limb control due to pathology or normal aging. In turn, theoretical models of speed-accuracy and goal-directed movement can help one identify and, in some cases, develop instructional or environmental interventions to temper the impact of an atypical perceptual-motor system on performance (e.g., Cicchetti \& Toth, 2009). Based on this logic, our research has been particularly interested in perceptual-motor performance in adolescents and young adults with Down syndrome, Williams syndrome, and autism spectrum disorder. More recently, we have started to examine the impact of normal aging on goal-directed reaching and aiming. People associated with all these groups typically perform slower movements, to achieve the same degree of accuracy, compared with young adults from the general population. However, despite similarities in overall speed and accuracy outcomes, kinematic data indicate that reaching and aiming are compromised in these groups for some very specific reasons. As we discuss next, the types of difficulties are consistent with one or more aspects of our multiple-process model of limb control. 


\section{Down Syndrome and Williams Syndrome}

Down syndrome and Williams syndrome are genetically based disorders that produce a distinct constellation of anatomical, neurophysiological, and cognitive characteristics (Bellugi, Lichtenberger, Mills, Galaburda, \& Korenberg, 1999; Elliott, 2005; Wang, Doherty, Hesselink, \& Bellugi, 1992). Thus, although children and adults from both groups generally exhibit overall deficits in intellectual functioning, each of the two syndromes is associated with a specific set of cognitive and perceptual-motor strengths and weaknesses when compared with other groups of people with and without intellectual handicaps. For example, persons with Down syndrome have difficulty performing precision goal-directed movement with any degree of speed or efficiency.

The problem that adults with Down syndrome have in performing precision goal-directed movements is apparent in Figure 4, where we have depicted representative acceleration profiles from two simple aiming movements (Hodges, Cunningham, Lyons, Kerr, \& Elliott, 1995; see also Elliott, Welsh, Lyons, Hansen, \& Wu, 2006; Hansen, Sheahan, et al., 2005). The first thing to notice is that the movement performed by the person with Down syndrome took twice as long to complete. This extended movement time is partly because of a lower peak in the magnitude of acceleration, but the primary reason for the extra time is associated with the multiple discontinuities in acceleration after peak velocity was achieved. These discontinuities are usually thought to reflect feedback-based corrections designed to reduce the degree of discrepancy between the position of the limb and the target (i.e., limb-target control). Because these corrections are necessary, the assumption is that the performers with Down syndrome have problems with movement planning and feed-forward control. This notion is consistent with data from a very different type of experiment designed to examine the anticipatory awareness of selfinitiated movement.

In one of the early experiments designed to examine anticipatory awareness of action, Libet, Gleason, Wright, and Pearl (1983) had participants watch a small rotating clock hand. Their task was to perform a voluntary wrist movement while watching the clock and later report the position of the hand on the clock face when the movement was made. It is interesting that the perception of the movement initiation was $80-90 \mathrm{~ms}$ ahead of its actual execution and coincided with neural activity in the premotor areas of the brain associated with the movement planning process (i.e., rather

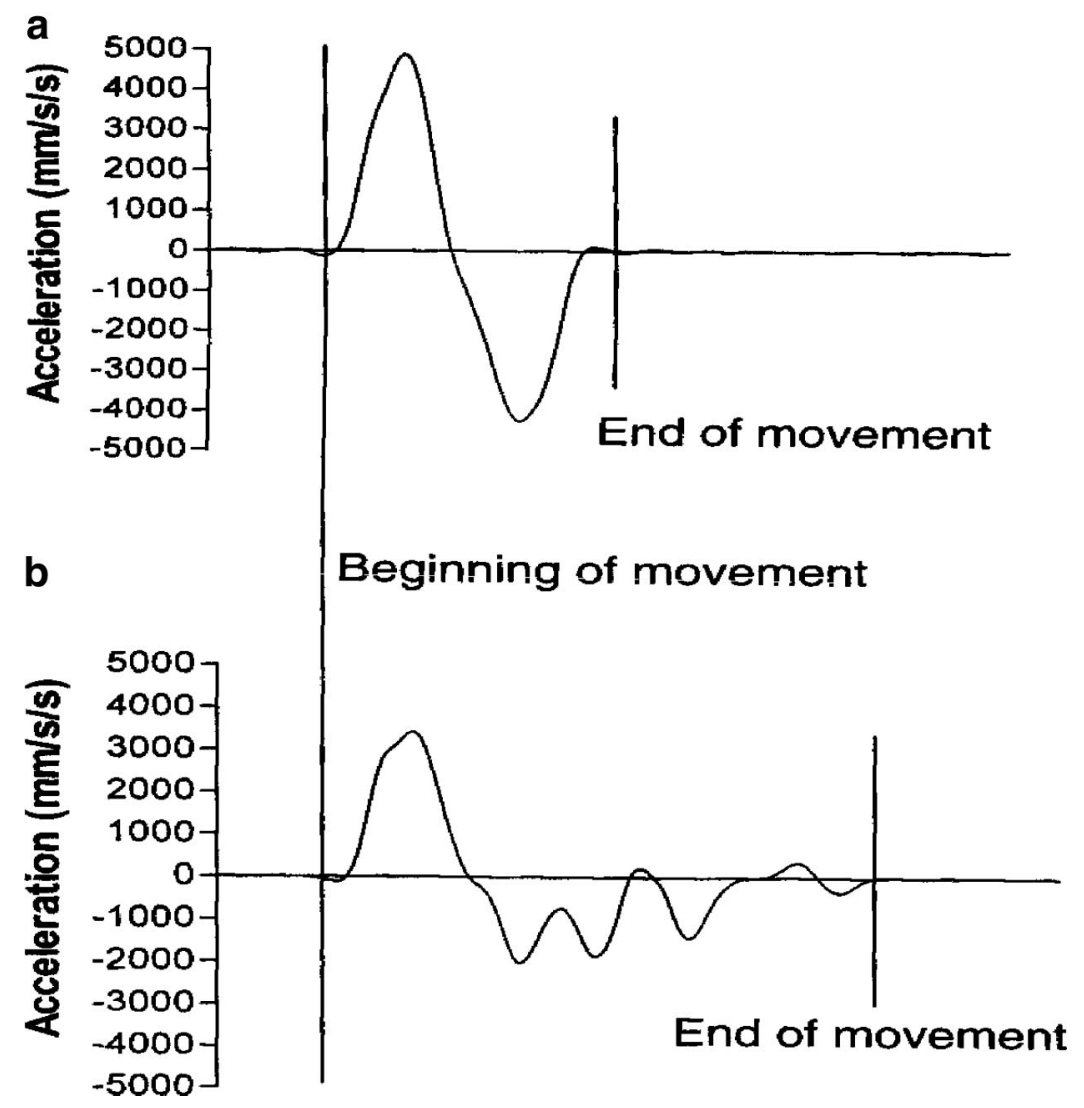

Figure 4. Representative acceleration profiles from an adult without (a) and with (b) Down syndrome. These profiles are from a $13-\mathrm{cm}$ one-dimensional computer aiming movements away from the body with full vision (Welsh \& Elliott, 2000). From "Preparation and Control of Goal-Directed Limb Movements in Persons With Down Syndrome," by T. N. Welsh and D. Elliott, in Perceptual-Motor Behavior in Down Syndrome (p. 61), edited by D. J. Weeks, R. Chua, and D. Elliott, 2000, Champaign, IL: Human Kinetics. Copyright 2000 by Human Kinetics Publishers. Reprinted with permission. 
than the muscular activity associated with movement execution). The notion is that, for most people, the awareness of action is linked to the generation of an internal representation for either the action per se or the predicted sensory consequences of the upcoming action. As outlined earlier, these representations of action and their expected sensory consequences are often referred to as internal forward models (Kawato \& Wolpert, 1998; Miall \& Wolpert, 1996; Wolpert \& Flanagan, 2001), and they are formed as part of the movement preparation process. These internal models are thought to be important for not only feed-forward motor control but also rapid feedback-based control (see Elliott et al., 2009, for a review). The latter occurs when there is a mismatch between the actual and the expected sensory consequences of a movement. This type of comparison is thought to underpin the very early control of limb velocity (see Grierson \& Elliott, 2008, 2009a) and limb direction (Hansen et al., 2007) in the types of movements depicted in Figure 4.

In the context of our multiple-process model, Obhi et al. (2007) conducted a study similar to Libet et al.'s (1983) involving adults with Down syndrome and found that they did not exhibit anticipatory awareness. Their perception of a self-generated finger press was $110 \mathrm{~ms}$ after the actual movement. The control participants judged the movement to be $75 \mathrm{~ms}$ earlier than it really was. Obhi et al. concluded that adults with Down syndrome were judging the temporal onset of their movements based on proprioceptive and visual feedback that resulted from the execution of the movement rather than on the planning process (i.e., an internal forward model).

This notion of adapted control is also consistent with findings by Bunn, Roy, and Elliott (2007), who reported that children with Down syndrome had greater difficulty pantomiming a movement than performing concurrent imitation. This type of difficulty was apparent regardless of the presentation mode (see also Bunn, Simon, Welsh, Watson, \& Elliott, 2002; Zoia, Pelamatti, \& Rumiati, 2004). In combination, such findings suggest that persons with Down syndrome have trouble forming a stable representation of the to-beperformed action and are dependent on direct visual information for performance. In terms of our model, the implication is that in Down syndrome, forward-modeled, but not discrete feedbackdriven, online control is compromised.

Aiming movements in young adults with Williams syndrome are even more compromised than those exhibited by persons with Down syndrome of a similar chronological and mental age. For example, Elliott et al. (2006) found that persons with Williams syndrome had longer movement times and a greater number of discontinuities in their aiming profiles than persons with either Down syndrome or undifferentiated intellectual handicaps. Once again, it appears that this group of people is compromised with respect to feed-forward control and impulse control associated with the expected sensory consequences of action. This problem makes them very dependent on discrete target control, late in the movement. This dissociation between intact limb-target control and a compromised internal model for online impulse control is consistent with the notion that these two control processes can operate independently (Grierson \& Elliott, 2008, 2009a, 2009b).

Although we have so far avoided any reference to the neural correlates associated with impulse and limb-target control, it is worth mentioning that the aiming behavior of young adults with Williams syndrome is consistent with the hypothesis that these people have a specific dorsal stream deficit (e.g., Atkinson et al., 1997). This system represents space egocentrically and is thought to play a major role in the visual-motor processing necessary for real-time regulation of goal-directed movement (e.g., Milner \& Goodale, 1995). In the context of our model, this type of control would involve a comparison of expected sensory consequences to perceived sensory consequences.

\section{Autism Spectrum Disorder}

Autism is a developmental disorder that negatively impacts the ability to form interpersonal relationships and develop effective communication skills (Dawson \& Toth, 2006; Szatmari, Tuff, Finlayson, \& Bartolucci, 1990). Autism spectrum disorder also affects executive function and the way a person interacts with his or her environment (Hill, 2004). These latter two difficulties appear to extend to the organization and control of goal-directed movement (Hughes, 1996).

Young adults with autism spectrum disorder who function within the normal range of intelligence take up to $50 \%$ longer to execute accuracy-constrained aiming movement than other adults of the same age (Glazebrook, Elliott, \& Lyons, 2006). Movement time differences between the two groups are most pronounced when the accuracy constraints of the aiming situation are high. It is interesting, however, that the velocity and acceleration profiles associated with their aiming movements look similar to those of control participants from the general population. The profiles of persons with autism are simply flatter and more elongated (i.e., they reach lower peak accelerations and deceleration but do so at proportionally similar times in the movement). Aside from these differences in the magnitude of acceleration and deceleration, our analyses indicated that qualitative differences between the groups existed in trial-to-trial spatial variability. Specifically, persons with autism exhibited far greater trial-to-trial spatial variability at peak acceleration than control participants (Glazebrook et al., 2006). The larger spatial variability at peak acceleration was particularly evident for higher index-of-difficulty movements (see Fitts, 1954). However, differences in spatial variability between the groups diminished between peak acceleration and peak velocity and then again between peak velocity and peak deceleration. By movement termination, persons with autism spectrum disorder were just as spatially consistent as their same-age peers.

In contrast to those of persons with Down syndrome, the longer movement times of young adults with autism were not related to multiple discontinuities (i.e., discrete corrections) during deceleration. In fact, their movement trajectories are consistent with a form of smooth continuous control that has an impact on spatial variability prior to peak velocity. Thus their overall slowness reflects greater variability in the specification of the initial muscular forces designed to propel the limb toward the target and/or the timing of those forces (see Figure 5). The online control processes associated with correcting force production error appear to be uncompromised. That is, both impulse and limb-target control are intact in this group and, if anything, are more important for endpoint accuracy because of increased neural-motor noise associated with movement execution. In keeping with our model, the working hypothesis is that persons with autism chose to make less forceful (i.e., slower) movements in order to temper the impact of a noisy movement production system (i.e., variability specifi- 


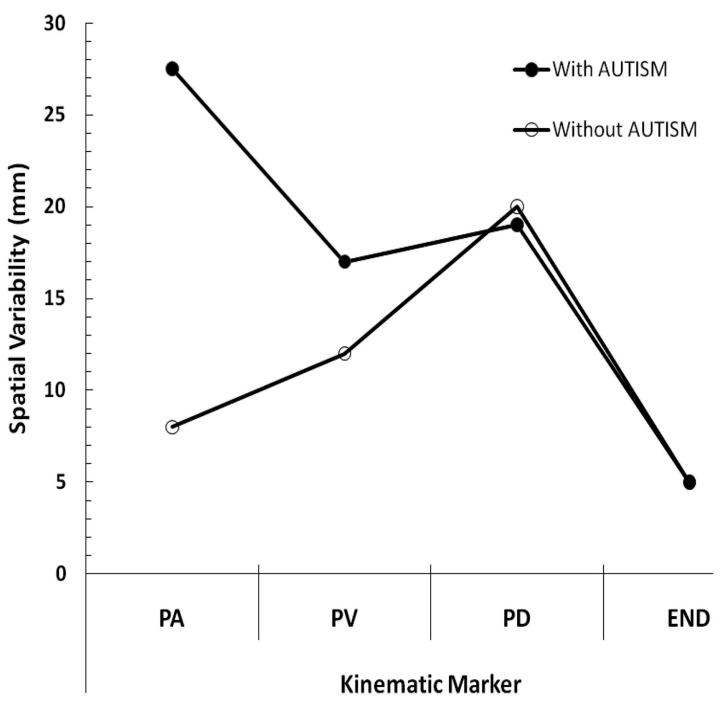

Figure 5. Trial-to-trial within-participant standard deviation in displacement in the primary direction of the movement at peak acceleration (PA), peak velocity (PV), peak deceleration (PD), and end of the movement (END) for young adults with and without autism spectrum disorder. The target was $32 \mathrm{~cm}$ from the home position and $2 \mathrm{~cm}$ in diameter. Note that, on average, participants with autism took $440 \mathrm{~ms}$ to complete movements of this difficulty, whereas participants without autism took $265 \mathrm{~ms}$. Adapted from "A Kinematic Analysis of How Young Adults With and Without Autism Plan and Control Goal-Directed Movements," by C. M. Glazebrook, D. Elliott, and J. Lyons, 2006, Motor Control, 10, p. 258. Copyright 2006 by Human Kinetics Publishers.

cation and production of muscular force; see Figure 3). However, even with slower movements, more time is still required for online control. As an aside, it is probably worth noting that persons with autism have been shown to exhibit the same pattern of anticipatory awareness as other adults when performing a Libet et al. (1983)type task (Glazebrook, Elliott, \& Lyons, 2008; cf. Down syndrome). In line with our earlier reasoning, this would indicate that these people are quite capable of forming a stable internal representation of the to-be-performed action at the time of movement planning. ${ }^{4}$

\section{Normal Aging}

Along with the other physical, sensory, and cognitive changes that take place with age (Salthouse, 2009), there is a progressive deterioration in the speed at which goal-directed actions are performed (e.g., Rabbitt, 1979; Salthouse, 1979). The majority of the additional time to complete accuracy-constrained aiming movements is associated with the time after peak velocity, and typically the time between peak deceleration and the end of the movement (Cooke, Brown, \& Cunningham, 1989; Darling, Cooke, \& Brown, 1989; Goggin \& Stelmach, 1990; Welsh, Higgins, \& Elliott, 2007). This latter portion of the trajectory is usually associated with target control (Carlton, 1992; Chua \& Elliott, 1993). The idea that older adults spend more time in late feedback-based regulation is consistent with the finding that, on average, their primary submovements undershoot the target to a greater degree than the primary submovements of young adults (Ketcham, Seidler, Van Gemmert,
\& Stelmach, 2002; Pratt, Chasteen, \& Abrams, 1994; cf. Welsh et al., 2007). Older adults also exhibit a greater number of corrective submovements near the end of the movement than young adults (Lyons, Elliott, Swanson, \& Chua, 1996). Teeken et al. (1996) have also revealed evidence of an age-related decline of the ability of individuals to process online sensory feedback and produce movement corrections, especially when completing discrete rather than reciprocal aiming tasks. In other words, the age-related decline might be caused by the delays in detecting the movement error through sensory feedback, determining a movement correction, and then producing the correction through a physiological system that is degenerating.

Although it has been suggested that older people are more dependent on feedback-based control because of deterioration in their ability to produce reliable muscular forces (Galganski, Fuglevand, \& Enoka, 1993), this hypothesis is inconsistent with kinematic data indicating that older performers exhibit no more temporal or spatial variability during the early portions of their aiming trajectories than young performers (e.g., Welsh et al., 2007; see Figure 6). It seems more likely that older adults learn to adopt a play-it-safe strategy at the preplanning stage of movement (see Figure 3). A cautious strategic approach to limb control minimizes temporal and energy costs associated with overshooting errors. The aiming trajectories of older adults may reflect an adaptive strategy that permeates a number of perceptual-motor activities, because there are often greater safety implications associated with target overshooting than undershooting in many everyday situations (e.g., Rabbitt, 1981; Salthouse, 1979). That is, older adults are generally more concerned with accuracy than speed and adopt reaching strategies that are designed to minimize energy-costly errors as well as those often associated with accident or injury (e.g., Folkard, 2008). Research involving the examination of trialto-trial changes in aiming behavior, under conditions in which the costs and benefits associated with different types of error are manipulated, needs to be conducted to test this hypothesis.

\section{Summary}

The special-populations section of this article was not meant to be exhaustive. Rather our goal was to demonstrate that the perceptual-motor slowing, found in a number of special populations, occurs for very different reasons. In the context of our multiple-process model, we chose to examine three groups that exhibit unique movement trajectories compared with young healthy adults. In this way, we were able to highlight the importance of neural-motor noise (e.g., autism), feed-forward and early dynamic control (e.g., Down and Williams syndrome) and late, strategic control (e.g., normal aging) in precision aiming. We believe our model has the potential to provide a theoretical framework for examining movement pathology in these and other special populations. One strength of the multiple-process model is that

\footnotetext{
${ }^{4}$ Although persons with autism appear able to form viable internal representations of their own self-generated actions for feed-forward and online control, there is a growing body of evidence to indicate that they may not be able to form similar internal models of action by observing the behavior of others (e.g., Welsh, Ray, Weeks, Dewey, \& Elliott, 2009). It has been suggested that this problem is related to dysfunction of the mirror neuron system (e.g., Iacoboni \& Dapretto, 2006).
} 


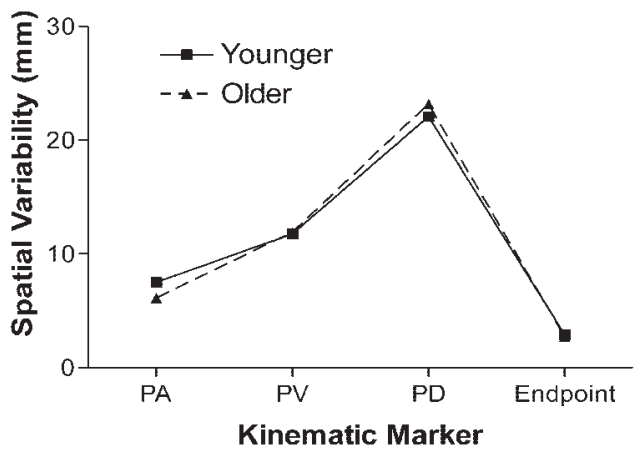

Figure 6. Trial-to-trial within-participant standard deviation in displacement in the primary direction of the movement at peak acceleration (PA), peak velocity (PV), peak deceleration (PD), and end of the movement (END) for a two-dimensional aiming movement away from the body. On average the movement times of the older and younger participants were $453 \mathrm{~ms}$ and $382 \mathrm{~ms}$, respectively. The majority of this difference was associated with the time after peak velocity (233 ms for young participants and $283 \mathrm{~ms}$ for older participants). Adapted from "Are There Age-Related Differences in Learning to Optimize Speed, Accuracy, and Energy Expenditure?" by T. N. Welsh, L. Higgins, and D. Elliott, 2007, Human Movement Science, 26, p. 904. Copyright 2007 by Elsevier.

it deals not only with single-trial performance but also with how performance changes from trial to trial and following extended practice. The impact of practice on performance is of obvious importance in the context of education and rehabilitation of persons with special needs. It is our contention that a process-oriented model of limb control, such as the multiple-process model, could provide insights into what type of practice will be of most benefit to particular groups.

\section{Summary and Conclusions}

People typically organize their reaching and aiming movements to achieve the precision dictated by the task demands, while optimizing movement speed and energy efficiency. When faced with unexpected changes to the task demands, they are usually quite adept at adjusting their movement trajectories to accommodate the new environmental constraints. In this article, we presented a multiple-process model of limb control that attempts to capture the efficiency and flexibility of goal-directed reaching and aiming. The model builds on Woodworth's (1899) two-component description of limb control and its 20th-century variants (Elliott et al., 2001; Meyer et al., 1988).

Our multiple-process model of limb control incorporates ideas from engineering and neuroscience about forward modeling in movement preparation and execution with models of limb control from the psychological literature developed to explain Fitts's law (e.g., Meyer et al., 1988). In this respect, although the individual components of our model are not new, our model combines aspects to two motor control literatures that have evolved in parallel without a great deal of cross talk. Our specific formulation relies heavily on recent work (e.g., Grierson \& Elliott, 2009a) that has been successful in dissociating online control of the initial movement impulse (e.g., Proteau \& Masson, 1997) from late feedbackbased control in situations that involve minimizing the discrepancy between limb and target position late in the movement (e.g., Meyer et al., 1988).

Our multiple-process model of limb control requires one to understand not only the nature of individual limb trajectories but also how spatial-central tendency and variability, and associated representation for limb control, unfold over a series of trials and more extended practice (Elliott et al., 2004; Worringham, 1991). In this context, the model helps one understand various aspects of motor learning, including specificity of learning in goal-directed aiming (e.g., Proteau et al., 1987, 1992). Additionally, we propose that the model can be used to isolate the breakdown in precision reaching and aiming due to pathology (Elliott \& Bunn, 2004) and normal aging (Pratt et al., 1994).

To make the presentation of our model more manageable, we deliberately avoided delving into the neural correlates of the limb control processes we describe. The exclusion of these correlates from the review does not mean that a neurophysiological literature in this area does not exist. On the contrary, there is evidence from patients with discrete lesions, studies employing brain imaging and stimulation techniques, as well as behavioral protocols, which have sought to identify the neural systems associated with feedforward- and feedback-based limb control. For example, recent functional MRI studies by Bogacz et al. (2010) have linked specific premotor and association areas of the cortex to strategic speed-accuracy trade-off decision making in goal-directed movement. Other imaging, transcranial magnetic stimulation and patient work has shown that the superior parietal areas of the brain are involved in the comparison of the expected and perceived sensory consequences of movement and could be important for rapid online control (e.g., Coslett et al., 2008; Desmurget et al., 1999; see also Glover, 2004; Milner \& Goodale, 1995). In a similar vein, we are currently conducting a series of transcranial magnetic stimulation studies designed to dissociate the two types of visual online control with direct perturbations to the associated neural systems. As well, we continue to work with special populations suffering from very specific limb control problems. As discussed earlier, it is often the case that insights into typical perceptualmotor function can be gleaned by examining the breakdown of precision behavior due to pathology or normal aging. It is our intention to use the proposed multiple-process model to guide our experimentation and hence further understanding of the control and learning of goal-directed action.

\section{References}

Abrams, R. A., \& Pratt, J. (1993). Rapid aimed limb movements: Differential effects of practice on component submovements. Journal of Motor Behavior, 25, 288-298.

Angel, R. W., \& Higgins, J. R. (1969). Correction of false moves in pursuit tracking. Journal of Experimental Psychology, 82, 185-187. doi: $10.1037 / \mathrm{h} 0028032$

Atkinson, J., King, J., Braddick, O., Nokes, L., Anker, S., \& Braddick, F. (1997). A specific deficit of dorsal stream function in Williams' syndrome. NeuroReport, 8, 1919-1922. doi:10.1097/00001756199705260-00025

Bard, C., Hay, L., \& Fleury, M. (1985). Role of peripheral vision in the directional control of rapid aiming movements. Canadian Journal of Experimental Psychology, 39, 151-161. doi:10.1037/h0080120

Barral, J., \& Debû, B. (2002). Hand and gender differences in the organization of aiming in 5-year-old children. Neuropsychologia, 40, 152-161. doi:10.1016/S0028-3932(01)00080-X 
Beggs, W. D. A., \& Howarth, C. I. (1970). Movement control in a repetitive motor task. Nature, 225, 752-753. doi:10.1038/225752a0

Beggs, W. D. A., \& Howarth, C. I. (1972). The accuracy of aiming at a target: Some further evidence for a theory of intermittent control. Acta Psychologica, 36, 171-177. doi:10.1016/0001-6918(72)90001-7

Bellugi, U., Lichtenberger, L., Mills, D., Galaburda, A., \& Korenberg, J. (1999). Bridging cognition, the brain and molecular genetics: Evidence from Williams syndrome. Trends in Neuroscience, 22, 197-207. doi: 10.1016/S0166-2236(99)01397-1

Binsted, G., \& Elliott, D. (1999). Ocular perturbations and retinal/ extraretinal information: The coordination of saccadic and manual movements. Experimental Brain Research, 127, 193-206. doi:10.1007/ s002210050789

Bogacz, R., Wagenmakers, E.-J., Forstmann, B. U., \& Nieuwenhuis, S. (2010). The neural basis of speed-accuracy tradeoff. Trends in Neuroscience, 33, 10-16. doi:10.1016/j.tins.2009.09.002

Bunn, L., Roy, E. A., \& Elliott, D. (2007). Speech perception and motor control in children with Down syndrome. Child Neuropsychology, 13, 262-275. doi:10.1080/09297040600770738

Bunn, L., Simon, D. A., Welsh, T. N., Watson, C., \& Elliott, D. (2002). Speech production errors in adults with and without Down syndrome following verbal, written, and pictorial cues. Developmental Neuropsychology, 21, 157-172. doi:10.1207/S15326942DN2102_3

Carlton, L. G. (1981). Visual information: The control of aiming movements. Quarterly Journal of Experimental Psychology: Human Experimental Psychology, 33A, 87-93. doi:10.1080/14640748108400771

Carlton, L. G. (1992). Visual processing time and the control of movement. In L. Proteau \& D. Elliott (Eds.), Vision and motor control (pp. 3-31). Amsterdam, the Netherlands: North-Holland. doi:10.1016/S01664115(08)62008-7

Cheng, D. T., Luis, M., \& Tremblay, L. (2008). Randomizing visual feedback in manual aiming: Reminiscence of the previous trial condition and prior knowledge of feedback availability. Experimental Brain Research, 189, 403-410. doi:10.1007/s00221-008-1436-3

Chicoine, A.-J., Lassonde, M., \& Proteau, L. (1992). Developmental aspects of sensorimotor integration. Developmental Neuropsychology, 8, 381-394. doi:10.1080/87565649209540533

Chua, R., \& Elliott, D. (1993). Visual regulation of manual aiming. Human Movement Science, 12, 365-401. doi:10.1016/0167-9457(93)90026-L

Cicchetti, D., \& Toth, S. L. (2009). The past achievements and future promises of developmental psychopathology: The coming of age of a discipline. Journal of Child Psychology and Psychiatry, 50, 16-25. doi:10.1111/j.1469-7610.2008.01979.x

Cooke, J. D., Brown, S. H., \& Cunningham, D. A. (1989). Kinematics of arm movements in elderly humans. Neurobiology of Aging, 10, 159165. doi:10.1016/0197-4580(89)90025-0

Coslett, H. B., Buxbaum, L. J., \& Schwoebel, J. (2008). Accurate reaching after active but not passive movements of the hand: Evidence for forward modeling. Behavioural Neurology, 19, 117-125.

Cressman, E. K., Franks, I. M., Enns, J. T., \& Chua, R. (2006). No automatic pilot for visually guided aiming based on colour. Experimental Brain Research, 171, 174-183. doi:10.1007/s00221-005-0260-2

Crossman, E. R., \& Goodeve, P. J. (1983). Feedback control of handmovement and Fitts' law. Quarterly Journal of Experimental Psychology: Human Experimental Psychology, 35A, 251-278. doi:10.1080/ 14640748308402133

Darling, W. G., Cooke, J. D., \& Brown, S. H. (1989). Control of simple arm movements in elderly humans. Neurobiology of Aging, 10, 149157. doi:10.1016/0197-4580(89)90024-9

Davidson, P. R., \& Wolpert, D. M. (2005). Widespread access to predictive models in the motor system: A short review. Journal of Neural Engineering, 2, S313-S319. doi:10.1088/1741-2560/2/3/S11

Dawson, G., \& Toth, K. (2006). Autism spectrum disorders. In D. Cicchetti
\& D. J. Cohen (Eds.), Developmental psychopathology: Vol. 3. Risk, disorder, and adaptation (2nd ed., pp. 317-357). New York, NY: Wiley.

Desmurget, M., Epstein, C. M., Turner, R. S., Prablanc, C., Alexander, G. E., \& Grafton, S. T. (1999). Role of the posterior parietal cortex in updating reaching movements to a visual target. Nature Neuroscience, 2 , 563-567. doi:10.1038/9219

Desmurget, M., \& Grafton, S. (2000). Forward modeling allows feedback control for fast reaching movements. Trends in Cognitive Sciences, 4, 423-431. doi:10.1016/S1364-6613(00)01537-0

Dugas, C., \& Marteniuk, R. G. (1989). Strategy and learning effects on perturbed movements: An electromyographic and kinematic study. Behavioural Brain Research, 35, 181-193. doi:10.1016/S01664328(89)80140-8

Elliott, D. (1988). The influence of visual target and limb information on manual aiming. Canadian Journal of Experimental Psychology, 42, 57-68. doi:10.1037/h0084172

Elliott, D. (2005). Down's syndrome. In B. Hopkins (Ed.), Cambridge encyclopedia of child development (pp. 429-432). Cambridge, England: Cambridge University Press.

Elliott, D., \& Allard, F. (1985). The utilization of visual feedback information during rapid pointing movements. Quarterly Journal of Experimental Psychology: Human Experimental Psychology, 37A, 407-425. doi:10.1080/14640748508400942

Elliott, D., Binsted, G., \& Heath, M. (1999). The control of goal-directed limb movements: Correcting errors in the trajectory. Human Movement Science, 18, 121-136. doi:10.1016/S0167-9457(99)00004-4

Elliott, D., \& Bunn, L. (2004). Motor disorders in children with intellectual disabilities. In D. Dewey \& D. E. Tupper (Eds.), Developmental motor disorders: A neuropsychological perspective (pp. 137-151). New York, NY: Guilford Press.

Elliott, D., Calvert, R., Jaeger, M., \& Jones, R. (1990). A visual representation and the control of manual aiming movements. Journal of Motor Behavior, 22, 327-346.

Elliott, D., Carson, R. G., Goodman, D., \& Chua, R. (1991). Discrete vs. continuous visual control of manual aiming. Human Movement Science, 10, 393-418. doi:10.1016/0167-9457(91)90013-N

Elliott, D., Chua, R., Pollock, B. J., \& Lyons, J. (1995). Optimizing the use of vision in manual aiming: The role of practice. Quarterly Journal of Experimental Psychology: Human Experimental Psychology, 48A, 7283. doi:10.1080/14640749508401376

Elliott, D., Hansen, S., \& Grierson, L. E. M. (2009). Optimising speed and energy expenditure in accurate visually directed upper limb movements. Ergonomics, 52, 438-447. doi:10.1080/00140130802707717

Elliott, D., Hansen, S., Mendoza, J., \& Tremblay, L. (2004). Learning to optimize speed, accuracy, and energy expenditure: A framework for understanding speed-accuracy relations in goal-directed aiming. Journal of Motor Behavior, 36, 339-351. doi:10.3200/JMBR.36.3.339-351

Elliott, D., Helsen, W. F., \& Chua, R. (2001). A century later: Woodworth's (1899) two-component model of goal-directed aiming. Psychological Bulletin, 127, 342-357. doi:10.1037/0033-2909.127.3.342

Elliott, D., \& Jaeger, M. (1988). Practice and the visual control of manual aiming movements. Journal of Human Movement Studies, 14, 279-291.

Elliott, D., \& Lee, T. D. (1995). The role of target information on manualaiming bias. Psychological Research, 58, 2-9. doi:10.1007/BF00447084

Elliott, D., Lyons, J., \& Dyson, K. (1997). Rescaling an acquired discrete aiming movement: Specific or general motor learning? Human Movement Science, 16, 81-96. doi:10.1016/S0167-9457(96)00041-3

Elliott, D., \& Madalena, J. (1987). The influence of premovement visual information on manual aiming. Quarterly Journal of Experimental Psychology: Human Experimental Psychology, 39A, 541-559. doi:10.1080/ 14640748708401802

Elliott, D., Welsh, T. N., Lyons, J., Hansen, S., \& Wu, M. (2006). The visual regulation of goal-directed reaching movements in adults with 
Williams syndrome, Down syndrome, and other developmental delays. Motor Control, 10, 34-54.

Engelbrecht, S. E., Berthier, N. E., \& O'Sullivan, L. P. (2003). The undershoot bias: Learning to act optimally under uncertainty. Psychological Science, 14, 257-261. doi:10.1111/1467-9280.03431

Evarts, E. V. (1973). Motor cortex reflexes associated with learned movement. Science, 179, 501-503. doi:10.1126/science.179.4072.501

Ferraz de Oliveira, R., Huys, R., Oudejans, R. R. D., van de Langenberg, R., \& Beek, P. J. (2007). Basketball jump shooting is controlled online by vision. Experimental Psychology, 54, 180-186. doi:10.1027/16183169.54.3.180

Ferraz de Oliveira, R., Oudejans, R. R. D., \& Beek, P. J. (2006). Late information pick-up is preferred in basketball jump shooting. Journal of Sports Sciences, 24, 933-940. doi:10.1080/02640410500357101

Ferrel, C., Bard, C., \& Fleury, M. (2001). Coordination in childhood: Modifications of visuomotor representations in 6- to 11-year-old children. Experimental Brain Research, 138, 313-321. doi:10.1007/ s002210100697

Fitts, P. M. (1954). The information capacity of the human motor system in controlling the amplitude of movement. Journal of Experimental Psychology, 47, 381-391. doi:10.1037/h0055392

Fitts, P. M., \& Peterson, J. R. (1964). Information capacity of discrete motor responses. Journal of Experimental Psychology, 67, 103-112. doi: $10.1037 / \mathrm{h} 0045689$

Folkard, S. (2008). Shift work, safety, and aging. Chronobiology International, 25, 183-198. doi:10.1080/07420520802106694

Galganski, M. E., Fuglevand, A. J., \& Enoka, R. M. (1993). Reduced control of motor output in human hand muscle of elderly subjects during submaximal contractions. Journal of Neurophysiology, 69, 2108-2115.

Ghez, C., Gordon, J., Ghilardi, M. F., \& Sainburg, R. (1995). Contributions of vision and proprioception to accuracy of limb movements. In M. S. Gazzaniga (Ed.), The cognitive neurosciences (pp. 549-564). Cambridge, MA: MIT Press.

Glazebrook, C. M., Dhillon, V. P., Keetch, K. M., Lyons, J., Amazeen, E., Weeks, D. J., \& Elliott, D. (2005). Perception-action and the Müller-Lyer illusion: Amplitude or endpoint bias? Experimental Brain Research, 160, 71-78. doi:10.1007/s00221-004-1986-y

Glazebrook, C. M., Elliott, D., \& Lyons, J. (2006). A kinematic analysis of how young adults with and without autism plan and control goaldirected movements. Motor Control, 10, 244-264.

Glazebrook, C. M., Elliott, D., \& Lyons, J. (2008). Temporal judgements of internal and external events in persons with and without autism. Consciousness and Cognition, 17, 203-209. doi:10.1016/j.concog .2007 .03 .001

Glover, S. (2004). Separate visual representations in the planning and control of action. Behavioral and Brain Sciences, 27, 3-24. doi:10.1017/ S0140525X04000020

Goggin, N. L., \& Stelmach, G. E. (1990). Age-related differences in a kinematic analysis of precued movements. Canadian Journal on Aging, 9, 371-385.

Goodale, M. A., \& Haffenden, A. (1998). Frames of reference for perception and action in the human visual system. Neuroscience and Biobehavioral Reviews, 22, 161-172. doi:10.1016/S0149-7634(97)00007-9

Gordon, J., Ghilardi, M. F., \& Ghez, C. (1994). Accuracy of planar reaching movements. I. Independence of direction and extent variability. Experimental Brain Research, 99, 97-111. doi:10.1007/BF00241415

Grierson, L. E. M., \& Elliott, D. (2008). Kinematic analysis of goaldirected aims made against early and late perturbations: An investigation of the relative influence of two online control processes. Human Movement Science, 27, 839-856. doi:10.1016/j.humov.2008.06.001

Grierson, L. E. M., \& Elliott, D. (2009a). Goal-directed aiming and the relative contribution of two online control processes. American Journal of Psychology, 122, 309-324.

Grierson, L. E. M., \& Elliott, D. (2009b). The impact of real and illusory target perturbations on manual aiming. Experimental Brain Research, 197, 279-285. doi:10.1007/s00221-009-1912-4

Grierson, L. E. M., Gonzalez, C., \& Elliott, D. (2009). Kinematic analysis of early online control of goal-directed reaches: A novel movement perturbation study. Motor Control, 13, 280-296.

Hansen, S., Cullen, J. D., \& Elliott, D. (2005). Self-selected visual information during discrete manual aiming. Journal of Motor Behavior, 37, 343-347. doi:10.3200/JMBR.37.5.343-347

Hansen, S., \& Elliott, D. (2009). Three-dimensional manual responses to unexpected target perturbations during rapid aiming. Journal of Motor Behavior, 41, 16-29.

Hansen, S., Elliott, D., \& Khan, M. A. (2008). Quantifying the variability of three-dimensional aiming movements using ellipsoids. Motor Control, 12, 241-251.

Hansen, S., Elliott, D., \& Tremblay, L. (2007). Online control of discrete action following visual perturbation. Perception, 36, 268-287. doi: $10.1068 / \mathrm{p} 5629$

Hansen, S., Glazebrook, C. M., Anson, J. G., Weeks, D. J., \& Elliott, D. (2006). The influence of advance information about target location and visual feedback on movement planning and execution. Canadian Journal of Experimental Psychology, 60, 200-208. doi:10.1037/cjep2006019

Hansen, S., Sheahan, B., Wu, M., Lyons, J. L., Welsh, T. N., \& Elliott, D. (2005). Specificity of learning in adults with and without Down syndrome. Adapted Physical Activity Quarterly, 22, 237-252.

Hansen, S., Tremblay, L., \& Elliott, D. (2005). Part and whole practice: Chunking and online control in the acquisition of a serial motor task. Research Quarterly for Exercise and Sport, 76, 60-66.

Hay, L. (1978). Accuracy of children on an open-loop pointing task. Perceptual and Motor Skills, 47, 1079-1082.

Hay, L. (1979). Spatial-temporal analysis of movements in children: Motor programs versus feedback in the development of reaching. Journal of Motor Behavior, 11, 189-200.

Heath, M. (2005). Role of limb and target vision in the online control of memory-guided reaches. Motor Control, 9, 281-311.

Heath, M., Hodges, N. J., Chua, R., \& Elliott, D. (1998). On-line control of rapid aiming movements: Unexpected target perturbations and movement kinematics. Canadian Journal of Experimental Psychology, 52, 163-173. doi: $10.1037 / \mathrm{h} 0087289$

Helsen, W. F., Elliott, D., Starkes, J. L., \& Ricker, K. L. (1998). Temporal and spatial coupling of point of gaze and hand movements in aiming. Journal of Motor Behavior, 30, 249-259. doi:10.1080/ 00222899809601340

Helsen, W. F., Elliott, D., Starkes, J. L., \& Ricker, K. L. (2000). Coupling of eye, finger, elbow, and shoulder movements during manual aiming. Journal of Motor Behavior, 32, 241-248. doi:10.1080/00222890009601375

Henderson, S. E. (1977). Role of feedback in the development and maintenance of a complex skill. Journal of Experimental Psychology: Human Perception and Performance, 3, 224-233. doi:10.1037/00961523.3.2.224

Hill, E. L. (2004). Executive dysfunction in autism. Trends in Cognitive Sciences, 8, 26-32. doi:10.1016/j.tics.2003.11.003

Hodges, N. J., Cunningham, S. J., Lyons, J., Kerr, T. L., \& Elliott, D. (1995). Visual feedback processing and goal-directed movement in adults with Down syndrome. Adapted Physical Activity Quarterly, 12, $176-186$.

Hughes, C. (1996). Brief report: Planning problems in autism at the level of motor control. Journal of Autism and Developmental Disorders, 26, 99-106. doi:10.1007/BF02276237

Iacoboni, M., \& Dapretto, M. (2006). The mirror neuron system and the consequences of its dysfunction. Nature Reviews Neuroscience, 7, 942 951. doi: $10.1038 / \mathrm{nrn} 2024$

Kawato, M., \& Wolpert, D. M. (1998). Internal models for motor control. Novartis Foundation Symposium, 218, 291-304. doi:10.1002/ 9780470515563 
Keele, S. W. (1968). Movement control in skilled motor performance. Psychological Bulletin, 70, 387-403. doi:10.1037/h0026739

Keele, S. W. (1981). Behavioral analysis of movement. In V. B. Brooks (Ed.), Handbook of physiology: Section I: The nervous system: Vol. 2. Motor Control, Pt. 2 (pp. 1391-1414). Washington, DC: American Physiological Society.

Keele, S. W., \& Posner, M. I. (1968). Processing visual feedback in rapid movements. Journal of Experimental Psychology, 77, 155-158. doi: 10.1037/h0025754

Ketcham, C. J., Seidler, R. D., Van Gemmert, A. W. A., \& Stelmach, G. E. (2002). Age-related kinematic differences as influenced by task difficulty, target size, and movement amplitude. Journals of Gerontology: Series B. Psychological and Social Sciences, 57, P54-P64. doi:10.1093/ geronb/57.1.P54

Khan, M. A., Elliott, D., Coull, J., Chua, R., \& Lyons, J. (2002). Optimal control strategies under different feedback schedules: Kinematic evidence. Journal of Motor Behavior, 34, 45-57. doi:10.1080/ 00222890209601930

Khan, M. A., \& Franks, I. M. (2000). The effect of practice on component submovements is dependent on the availability of visual feedback. Journal of Motor Behavior, 32, 227-240. doi:10.1080/00222890009601374

Khan, M. A., Franks, I. M., Elliott, D., Lawrence, G. P., Chua, R., Bernier, P.-M., ... Weeks, D. J. (2006). Inferring online and offline processing of visual feedback in target-directed movements from kinematic data. Neuroscience and Biobehavioral Reviews, 30, 1106-1121. doi:10.1016/ j.neubiorev.2006.05.002

Khan, M. A., Franks, I. M., \& Goodman, D. (1998). The effect of practice on the control of rapid aiming movements: Evidence for an interdependency between programming and feedback processing. Quarterly Journal of Experimental Psychology: Human Experimental Psychology, 51A, 425-444. doi:10.1080/713755756

Khan, M. A., Lawrence, G., Fourkas, A., Franks, I. M., Elliott, D., \& Pembroke, S. (2003). Online versus offline processing of visual feedback in the control of movement amplitude. Acta Psychologica, 113, 83-97. doi:10.1016/S0001-6918(02)00156-7

Konczak, J., Borutta, M., Topka, H., \& Dichgans, J. (1995). The development of goal-directed reaching in infants: Hand trajectory formation and joint force control. Experimental Brain Research, 106, 156-168. doi: 10.1007/PL00005599

Konczak, J., \& Dichgans, J. (1997). The development toward stereotypic arm kinematics during reaching in the first 3 years of life. Experimental Brain Research, 117, 346-354. doi:10.1007/s002210050228

Kuhtz-Buschbeck, J. P., Stolze, H., Jöhnk, K., Boczek-Funcke, A., \& Illert, M. (1998). Development of prehension movements in children: A kinematic study. Experimental Brain Research, 122, 424-432. doi:10.1007/ s002210050530

Libet, B., Gleason, C. A., Wright, E. W., \& Pearl, D. K. (1983). Time of conscious intention to act in relation to onset of cerebral activity (readiness-potential): The unconscious initiation of a freely voluntary act. Brain, 106, 623-642. doi:10.1093/brain/106.3.623

Lyons, J., Elliott, D., Swanson, L. R., \& Chua, R. (1996). The use of vision in manual aiming by young and older adults. Journal of Aging and Physical Activity, 4, 165-178.

Lyons, J., Hansen, S., Hurding, S., \& Elliott, D. (2006). Optimizing rapid aiming behaviour: Movement kinematics depend on the cost of corrective modifications. Experimental Brain Research, 174, 95-100. doi: 10.1007/s00221-006-0426-6

Mackrous, I., \& Proteau, L. (2007). Specificity of practice results from differences in movement planning strategies. Experimental Brain Research, 183, 181-193. doi:10.1007/s00221-007-1031-z

Medina, J., Jax, S. A., \& Coslett, H. B. (2009). Two-component models of reaching: Evidence from deafferentation in a Fitts' law task. Neuroscience Letters, 451, 222-226. doi:10.1016/j.neulet.2009.01.002

Mendoza, J. E., Elliott, D., Meegan, D. V., Lyons, J. L., \& Welsh, T. N.
(2006). The effect of the Müller-Lyer illusion on the planning and control of manual aiming movements. Journal of Experimental Psychology: Human Perception and Performance, 32, 413-422. doi:10.1037/ 0096-1523.32.2.413

Messier, J., \& Kalaska, J. F. (1997). Differential effect of task conditions on errors of direction and extent of reaching movements. Experimental Brain Research, 115, 469-478. doi:10.1007/PL00005716

Messier, J., \& Kalaska, J. F. (1999). Comparison of variability of initial kinematics and endpoints of reaching movements. Experimental Brain Research, 125, 139-152. doi:10.1007/s002210050669

Meyer, D. E., Abrams, R. A., Kornblum, S., Wright, C. E., \& Smith, J. E. K. (1988). Optimality in human motor performance: Ideal control of rapid aimed movements. Psychological Review, 95, 340-370. doi: 10.1037/0033-295X.95.3.340

Meyer, D. E., Smith, J. E. K., Kornblum, S., Abrams, R. A., \& Wright, C. E. (1990). Speed-accuracy tradeoffs in aimed movements: Toward a theory of rapid voluntary action. In M. Jeannerod (Ed.), Attention and Performance XIII: Motor representation and control (pp. 173-226). Hillsdale, NJ: Erlbaum.

Miall, R. C., \& Wolpert, D. M. (1996). Forward models for physiological motor control. Neural Networks, 9, 1265-1279. doi:10.1016/S08936080(96)00035-4

Milner, A. D., \& Goodale, M. A. (1995). The visual brain in action. New York, NY: Oxford University Press.

Obhi, S. S., Lyons, J., Welsh, T. N., Glazebrook, C. M., Anson, G., \& Elliott, D. (2007). The perceived time of voluntary action for adults with and without Down syndrome. Down Syndrome Quarterly, 9, 4-9.

Oliveira, F. T. P., Elliott, D., \& Goodman, D. (2005). The energyminimization bias: Compensating for intrinsic influence of energyminimization mechanisms. Motor Control, 9, 101-114.

Paillard, J. (1980). The multichanneling of visual cues and the organization of a visually guided response. In G. E. Stelmach \& J. Requin (Eds.), Tutorial in motor behavior (pp. 259-279). Amsterdam, the Netherlands: North-Holland. doi:10.1016/S0166-4115(08)61950-0

Paillard, J. (1996). Fast and slow feedback loops for the visual correction of spatial errors in a pointing task: A reappraisal. Canadian Journal of Physiology and Pharmacology, 74, 401-417. doi:10.1139/cjpp-74-4401

Paillard, J., \& Amblard, B. (1985). Static versus kinetic visual cues for processing of spatial relationships. In D. J. Ingle, M. Jeannerod, \& D. N. Lee (Eds.), Brain mechanisms and spatial vision (pp. 367-385). Dordrecht, the Netherlands: Nijhoff.

Paulignan, Y., MacKenzie, C., Marteniuk, R., \& Jeannerod, M. (1991). Selective perturbations of visual input during prehension movements. 1. The effects of changing object position. Experimental Brain Research, 83, 502-512. doi:10.1007/BF00229827

Pélisson, D., Prablanc, C., Goodale, M. A., \& Jeannerod, M. (1986). Visual control of reaching movements without vision of the limb. II. Evidence of fast unconscious processes correcting the trajectory of the hand to the final position of a double-step stimulus. Experimental Brain Research, 62, 303-313. doi:10.1007/BF00238849

Pellizzer, G., \& Hauert, C.-A. (1996). Visuo-manual aiming movements in 6- to 10-year old children: Evidence for an asymmetric and asynchronous development of information processes. Brain and Cognition, 30, 175-193. doi:10.1006/brcg.1996.0011

Pew, R. W. (1966). Acquisition of hierarchical control over the temporal organization of a skill. Journal of Experimental Psychology, 71, 764771. doi: $10.1037 / \mathrm{h} 0023100$

Pratt, J., \& Abrams, R. A. (1996). Practice and component submovements: The roles of programming and feedback in rapid aimed limb movements. Journal of Motor Behavior, 28, 149-156.

Pratt, J., Chasteen, A. L., \& Abrams, R. A. (1994). Rapid aimed limb movements: Age differences and practice effects in component sub- 
movements. Psychology and Aging, 9, 325-334. doi:10.1037/08827974.9.2.325

Proteau, L. (1992). On the specificity of learning and the role of visual information for movement control. In L. Proteau \& D. Elliott (Eds.), Vision and motor control (pp. 67-103). Amsterdam, the Netherlands: North-Holland. doi:10.1016/S0166-4115(08)62011-7

Proteau, L. (2005). Visual afferent information dominates other sources of afferent information during mixed practice of a video-aiming task. Experimental Brain Research, 161, 441-456. doi:10.1007/s00221-0042090-z

Proteau, L., Marteniuk, R. G., Girouard, Y., \& Dugas, C. (1987). On the type of information used to control and learn an aiming movement after moderate and extensive practice. Human Movement Science, 6, 181199. doi:10.1016/0167-9457(87)90011-X

Proteau, L., Marteniuk, R. G., \& Lévesque, L. (1992). A sensorimotor basis for motor learning: Evidence indicating specificity of practice. Quarterly Journal of Experimental Psychology: Human Experimental Psychology, 44A, 557-575. doi:10.1080/14640749208401298

Proteau, L., \& Masson, G. (1997). Visual perception modifies goaldirected movement control: Supporting evidence from a visual perturbation paradigm. Quarterly Journal of Experimental Psychology: Human Experimental Psychology, 50A, 726-741. doi:10.1080/ 027249897391865

Proteau, L., Roujoula, A., \& Messier, J. (2009). Evidence for continuous processing of visual information in a manual video-aiming task. Journal of Motor Behavior, 41, 219-231. doi:10.3200/JMBR.41.3.219-231

Proteau, L., Tremblay, L., \& DeJaeger, D. (1998). Practice does not diminish the role of visual information in on-line control of a precision walking task: Support for the specificity of practice hypothesis. Journal of Motor Behavior, 30, 143-150. doi:10.1080/00222899809601331

Rabbitt, P. M. A. (1979). How old and young subjects monitor and control responses for accuracy and speed. British Journal of Psychology, 70, 305-311

Rabbitt, P. M. A. (1981). Sequential reactions. In D. H. Holding (Ed.), Human skill (pp. 147-170). London, England: Wiley.

Robin, C., Toussaint, L., Blandin, Y., \& Proteau, L. (2005). Specificity of learning in a video-aiming task: Modifying the salience of dynamic visual cues. Journal of Motor Behavior, 37, 367-376. doi:10.3200/ JMBR.37.5.367-376

Salthouse, T. A. (1979). Adult age and the speed-accuracy trade-off. Ergonomics, 22, 811-821. doi:10.1080/00140137908924659

Salthouse, T. A. (2009). When does age-related cognitive decline begin? Neurobiology of Aging, 30, 507-514. doi:10.1016/ j.neurobiolaging.2008.09.023

Saunders, J. A., \& Knill, D. C. (2003). Humans use continuous visual feedback from the hand to control fast reaching movements. Experimental Brain Research, 152, 341-352. doi:10.1007/s00221-003-1525-2

Saunders, J. A., \& Knill, D. C. (2004). Visual feedback control of hand movements. Journal of Neuroscience, 24, 3223-3234. doi:10.1523/ JNEUROSCI.4319-03.2004

Savelsbergh, G., von Hofsten, C., \& Jonsson, B. (1997). The coupling of head, reach and grasp movement in nine months old infant prehension. Scandinavian Journal of Psychology, 38, 325-333. doi:10.1111/14679450.00042

Schmidt, R. A., \& McCabe, J. F. (1976). Motor program utilization over extended practice. Journal of Human Movement Studies, 2, 239-247.

Schmidt, R. A., Zelaznik, H. N., \& Frank, J. S. (1978). Sources of inaccuracy in rapid movement. In G. E. Stelmach (Ed.), Information processing in motor control and learning (pp. 183-203). New York, NY: Academic Press.

Schmidt, R. A., Zelaznik, H., Hawkins, B., Frank, J. S., \& Quinn, J. T., Jr. (1979). Motor-output variability: A theory for the accuracy of rapid motor acts. Psychological Review, 86, 415-451. doi:10.1037/0033295X.86.5.415
Smeets, J. B. J., \& Brenner, E. (1995). Perception and action are based on the same visual information: Distinction between position and velocity. Journal of Experimental Psychology: Human Perception and Performance, 21, 19-31. doi:10.1037/0096-1523.21.1.19

Sparrow, W. A., \& Newell, K. M. (1998). Metabolic energy expenditure and the regulation of movement economy. Psychonomic Bulletin \& Review, 5, 173-196.

Starkes, J., Helsen, W., \& Elliott, D. (2002). A ménage à trois: The eye, the hand, and on-line processing. Journal of Sports Science, 20, 217-224. doi:10.1080/026404102317284772

Szatmari, P., Tuff, L., Finlayson, M. A., \& Bartolucci, G. (1990). Asperger's syndrome and autism: Neurocognitive aspects. Journal of the American Academy of Child and Adolescent Psychiatry, 29, 130-136. doi:10.1097/ 00004583-199001000-00021

Teeken, J. C., Adam, J. J., Paas, F. G. W. C., van Boxtel, M. P. J., Houx, P. J., \& Jolles, J. (1996). Effects of age and gender on discrete and reciprocal aiming movements. Psychology and Aging, 11, 195-198. doi:10.1037/0882-7974.11.2.195

Teuber, H.-L., \& Mishkin, M. (1954). Judgment of visual and postural vertical after brain injury. Journal of Psychology: Interdisciplinary and Applied, 38, 161-175.

Thelen, E., Corbetta, D., \& Spencer, J. P. (1996). Development of reaching during the first year: Role of movement speed. Journal of Experimental Psychology: Human Perception and Performance, 22, 1059-1076. doi: 10.1037/0096-1523.22.5.1059

Todorov, E. (2004). Optimality principles in sensorimotor control. Nature Neuroscience, 7, 907-915. doi:10.1038/nn1309

Tremblay, L., \& Proteau, L. (1998). Specificity of practice: The case of powerlifting. Research Quarterly for Exercise and Sport, 69, 284-289.

Trommershäuser, J., Gepshtein, S., Maloney, L. T., Landy, M. S., \& Banks, M. S. (2005). Optimal compensation for changes in task-relevant movement variability. Journal of Neuroscience, 25, 7169-7178. doi:10.1523/ JNEUROSCI.1906-05.2005

van Braeckel, K., Butcher, P. R., Geuze, R. H., Stremmelaar, E. F., \& Bouma, A. (2007). Movement adaptations in 7- to 10-year-old typically developing children: Evidence for a transition in feedback-based motor control. Human Movement Science, 26, 927-942. doi:10.1016/ j.humov.2007.07.010

von Hofsten, C. (1979). Development of visually directed reaching: The approach phase. Journal of Human Movement Studies, 5, 160-178.

von Hofsten, C. (1991). Structuring of early reaching movements: A longitudinal study. Journal of Motor Behavior, 23, 280-292.

von Hofsten, C., \& Rösblad, B. (1988). The integration of sensory information in the development of precise manual pointing. Neuropsychologia, 26, 805-821. doi:10.1016/0028-3932(88)90051-6

von Holst, E. (1954). Relations between the central nervous system and the peripheral organs. British Journal of Animal Behaviour, 2, 89-94. doi:10.1016/S0950-5601(54)80044-X

Walker, N., Philbin, D., Worden, A., \& Smelcer, J. B. (1997). A program of parsing mouse movements into component submovements. Behavior Research Methods, Instruments, \& Computers, 29, 456-460.

Wallace, S. A., \& Newell, K. M. (1983). Visual control of discrete aiming movements. Quarterly Journal of Experimental Psychology: Human Experimental Psychology, 35A, 311-321.

Wang, P. P., Doherty, S., Hesselink, J. R., \& Bellugi, U. (1992). Callosal morphology concurs with neurobehavioral and neuropathological findings in two neurodevelopmental disorders. Archives of Neurology, 49, 407-411.

Welsh, T. N., \& Elliott, D. (2000). Preparation and control of goal-directed limb movements in persons with Down syndrome. In D. J. Weeks, R. Chua, \& D. Elliott (Eds.), Perceptual-motor behavior in Down syndrome (pp. 49-70). Champaign, IL: Human Kinetics.

Welsh, T. N., Higgins, L., \& Elliott, D. (2007). Are there age-related differences in learning to optimize speed, accuracy, and energy 
expenditure? Human Movement Science, 26, 892-912. doi:10.1016/ j.humov.2007.04.004

Welsh, T. N., Ray, M. C., Weeks, D. J., Dewey, D., \& Elliott, D. (2009). Does Joe influence Fred's action? Not if Fred has autism spectrum disorder. Brain Research, 1248, 141-148. doi:10.1016/j.brainres.2008.10.077

West, G. L., Welsh, T. N., \& Pratt, J. (2009). Saccadic trajectories receive online correction: Evidence for a feedback-based system of oculomotor control. Journal of Motor Behavior, 41, 117-127. doi:10.3200/ JMBR.41.2.117-127

Westwood, D. A., \& Goodale, M. A. (2003). Perceptual illusion and the real-time control of action. Spatial Vision, 16, 243-254. doi:10.1163/ 156856803322467518

Whitney, D., Westwood, D. A., \& Goodale, M. A. (2003). The influence of visual motion on fast reaching movements to a stationary object. Letters to Nature, 423, 869-873. doi:10.1038/nature01693

Whitwell, R. L., Lambert, L. M., \& Goodale, M. A. (2008). Grasping future events: Explicit knowledge of the availability of visual feedback fails to reliably influence prehension. Experimental Brain Research, 188, 603-611. doi:10.1007/s00221-008-1395-8

Wimmers, R. H., Savelsbergh, G. J. P., Beek, P. J., \& Hopkins, B. (1998).
Evidence for a phase transition in the early development of prehension. Developmental Psychobiology, 32, 235-248. doi:10.1002/(SICI) 1098-2302(199804)32:3<235::AID-DEV7>3.0.CO;2-P

Wolpert, D. M., \& Flanagan, J. R. (2001). Motor prediction. Current Biology, 11, R729-R732. doi:10.1016/S0960-9822(01)00432-8

Woodworth, R. S. (1899). The accuracy of voluntary movement. Psychological Review, 3 (Monograph Suppl.), 1-119.

Worringham, C. J. (1991). Variability effects on the internal structure of rapid aiming movements. Journal of Motor Behavior, 23, 75-85.

Zelaznik, H. N., Hawkins, B., \& Kisselburgh, L. (1983). Rapid visual feedback processing in single-aiming movements. Journal of Motor Behavior, 15, 217-236.

Zoia, S., Pelamatti, G., \& Rumiati, R. I. (2004). Praxic skills in Down and mentally retarded adults: Evidence for multiple action routes. Brain and Cognition, 54, 7-17. doi:10.1016/S0278-2626(03)00055-1

Received October 22, 2009

Revision received June 24, 2010

Accepted June 25, 2010 